\title{
Combustion Plasma Electrical Conductivity Model Development for Oxy-Fuel MHD Applications
}

\author{
Clinton R. Bedick ${ }^{*}$, Lauren Kolczynski ${ }^{b, c}$, C. Rigel Woodside ${ }^{c}$ \\ ${ }^{a}$ U.S. Department of Energy, National Energy Technology Laboratory, 3610 Collins Ferry Rd., Morgantown, WV, \\ 26507, USA \\ ${ }^{b}$ University of Utah, 201 Presidents Circle, Salt Lake City, UT 84112, USA \\ 'U.S. Department of Energy, National Energy Technology Laboratory, 1450 Queen Avenue SW, Albany, OR, \\ 97321, USA
}

\author{
*Corresponding author (C.R. Bedick) \\ Email address: clinton.bedick@netl.doe.gov \\ Phone: (304)-285-5376
}

\begin{abstract}
:
Oxy-combustion can enable efficient $\mathrm{CO}_{2}$ capture from fossil fuel power plants in combined cycle systems; however, air separation is expensive. In order to directly utilize the high gas temperatures associated with oxycombustion and offset any oxygen separation penalties, a magnetohydrodynamic (MHD) generator has been proposed as a plant topping cycle. Accurately predicting the electrical conductivity of combustion products with the addition of potassium "seed" compound is necessary to evaluate the performance of this modern approach to MHD. In order to make these predictions, improved species collisional cross-section data (momentum transfer cross-section, MTCS) are needed at relevant conditions. A gas electrical conductivity model for use in open-cycle MHD power generation applications is presented, which makes use of updated MTCS data not represented in previous legacy publications.

Based on the results of a detailed review and analysis of currently available MTCS data relevant to open-cycle MHD combustion systems, recommendations have been provided for relevant species and a gas temperature range of 1500-3500 K ( 0.13-0.3 eV electron energy). Model predictions utilizing updated MTCS data are validated against limited experimental data found in literature for oxy-combustion with potassium seed compound. Model results are presented from a parametric study, which show the effect of combustion conditions and seeding on ionization processes and gas electrical conductivity, highlighting differences between modern oxy-combustion MHD systems and legacy approaches implementing air-fired combustion and high levels of preheat.
\end{abstract}

Keywords: oxy-fuel; oxy-combustion; MHD; magnetohydrodynamics; plasma; conductivity 


\section{Introduction}

Increasingly stringent emission regulations may force future and existing fossil fuel plant designs to consider some level of carbon dioxide $\left(\mathrm{CO}_{2}\right)$ capture. Carbon dioxide capture is greatly simplified in an oxy-combustion system as compared to conventional air-fired systems. In oxy-combustion systems, the flue gas is composed primarily of $\mathrm{CO}_{2}$ and water vapor $\left(\mathrm{H}_{2} \mathrm{O}\right)$. The $\mathrm{H}_{2} \mathrm{O}$ can be easily and efficiently condensed out, leaving a captureready $\mathrm{CO}_{2}$ stream. The biggest disadvantage of oxy-combustion is the significant capital and efficiency penalty associated with acquiring the oxygen via an air separation unit (ASU) [1]. It would thus be desirable if oxycombustion not only enabled $\mathrm{CO}_{2}$ capture, but also enabled additional power generation to offset the ASU costs. Such an approach is feasible through direct power extraction via a magnetohydrodynamic (MHD) generator. An MHD generator is capable of operating at full non-diluted oxy-combustion temperatures. Additionally, the direct power extraction will effectively cool the gasses to temperatures suitable for use in traditional turbine based power cycles. The MHD generator acts as a power cycle topping unit in this configuration and a more efficient combined cycle power plant with $\mathrm{CO}_{2}$ capture is realized.

MHD generators directly convert the kinetic and thermal energy of an electrically conductive fluid into electricity by driving it through a strong magnetic field and harvesting the electric potential generated by the Faraday Effect. In an open-cycle MHD power train, combustion products are fed directly into a generator channel, passing through the magnetic field, and creating a potential across electrodes inserted into the gas path. The gasses are then decelerated prior to entering the subsequent bottoming cycle(s). Figure 1 shows a generic opencycle MHD power train with a linear segmented faraday type MHD channel. In general, it can be said that the power density of an MHD channel is proportional to the gas velocity (u), magnetic field strength (B), and gas electrical conductivity $(\sigma)$ according to Eq. (1) [2].

$\mathrm{P} \propto \sigma \mathrm{u}^{2} \mathrm{~B}^{2}$

From Eq. (1), it can be seen that the MHD channel power density is linearly proportional to the electrical conductivity of the combustion gasses. In order to achieve adequate conductivity, a more readily ionized species, referred to as the "seed", is added to the combustion products. Group 1A elements are typically used due to their low ionization potentials, and a convenient compound to utilize is potassium carbonate $\left(\mathrm{K}_{2} \mathrm{CO}_{3}\right)$. Significantly, it will later be shown that the conductivity of seeded combustion gasses is quite sensitive to gas temperature. It is also notable that, because of the strong dependence of power on gas velocity, nozzles are used to accelerate the combustion products to near or greater than sonic velocities within the MHD channel. To generate the magnetic field, superconducting magnets are selected due to their ability to maintain high magnetic fields with very little electrical power consumption.

A great deal of MHD power generation research was conducted in the USA, USSR, Japan, and other countries from about 1960-1992, including the construction of several successful large scale demonstration facilities [2, 3]. Ultimately, the research was ramped down due to perceived economic disadvantages compared to existing commercial technologies. However, the motivation at the time did not need to consider $\mathrm{CO}_{2}$ capture, which has the potential to tremendously change the economics of fossil fuel power generation. Additionally, there have been significant developments in high temperature materials, superconducting magnets, and computational modeling over the past 25 years. These developments, along with the motivation for improved $\mathrm{CO}_{2} \mathrm{Capture}$ technology, has led the National Energy Technology Laboratory (NETL) to create an emerging R\&D effort exploring new topping cycle technologies such as MHD power generation. 
It is certainly conceivable that modern open-cycle MHD systems may look and perform very differently from early system designs. One factor to note is that legacy open-cycle systems envisioned utilizing enhanced air combustion or high temperature air pre-heaters ( $1500 \mathrm{~K}$ [2]) in order to achieve high combustion temperatures. In contrast, the need for $\mathrm{CO}_{2}$ capture today motivates us to eliminate nitrogen from the oxidant. Pure oxy-combustion yields higher gas temperatures, which increases the electrical conductivity, and in turn can yield higher MHD power densities. Notably, the temperature benefit of oxy-combustion was known to prior researchers but the high cost of ASU technologies at the time discouraged focus on this approach. Fortunately, the efficiency of an integrated ASU is nearly double what it was 30 years ago, and certainly could drop further based on thermodynamic limits [1].

In order to evaluate the present feasibility of MHD, improved modeling tools are needed; in particular, accurate predictions of gas electrical conductivity. This paper is dedicated to presenting the methodology for calculating the electrical conductivity of partially ionized combustion products, as well as discussing the results of a comprehensive literature survey leading to the development of updated species collisional cross-section data. Collisional cross-section data set recommendations have been provided for species relevant to open-cycle MHD combustion systems in the gas temperature range of 1500-3500 K ( 0.13-0.3 eV electron energy).

\section{Modeling Methodology}

In order to determine gas electrical conductivities for a variety of scenarios, predictions of combustion temperatures and species concentrations are required, including ions and free electrons. For this study, the primary focus was on methane $\left(\mathrm{CH}_{4}\right.$, main component of natural gas). However, comparisons are also made to limited experimental electrical conductivity data which can be found in the literature for oxy-combustion. In all cases, it was assumed that $\mathrm{K}_{2} \mathrm{CO}_{3}$ was utilized as a seed material, in aqueous solution.

\subsection{Combustion and Ionization Model}

An equilibrium combustion model was developed in Matlab using the Cantera chemical kinetics toolbox [4]. The Matlab/Cantera interface allowed programmatic evaluation of gas conditions for different fuel/oxidizer compositions, stoichiometry, or seed levels, and simplified the integration of an electrical conductivity model.

In order to determine relevant ion and free electron concentrations, a publicly available NASA gas phase thermodynamic and transport database $[5,6]$ was utilized. The NASA database, which is also implemented in the NASA chemical equilibrium with applications (CEA) software, contains values of heat capacity, enthalpy, and entropy for 1130 solid, liquid, and gaseous species [5]. From this data, equilibrium combustion product concentrations and adiabatic flame temperatures can be determined for a given reactant composition under conditions of constant enthalpy and pressure. Separate simulations were run under conditions of constant temperature and pressure in order to match published conditions for model validation or to examine temperature sensitivity. The results obtained all use the database's built-in considerations for high temperature dissociation, radical formation, and ionization

The present study only considers gas phase species. As a result, the following two decomposition reactions $[7,8]$ were assumed to occur to completion, which allowed seed concentrations to be specified in terms of gaseous potassium. In addition, small amounts of $\mathrm{CO}_{2}$ and $\mathrm{O}_{2}$ are produced and included in the reactant composition. Initial reactant temperatures were set at or above $400 \mathrm{~K}$ to ensure the potassium seed solution water was in gas phase. 
The approach utilized was not meant to simulate exact conditions within an actual MHD generator. Rather, the intent was to obtain meaningful gas composition inputs to the conductivity model for the purpose of comparative insight of theoretical MHD generator performance as a function of reactant composition and seed level. In addition, the approach facilitates comparisons between modern, oxy-combustion MHD systems and legacy systems implementing air-fired combustion and high levels of preheat.

\subsection{Electrical Conductivity Model}

A model of gas electrical conductivity was developed based on a review of prior publications [2, 9-11] while giving consideration to implementation of updated collisional cross-section data.

In general, when considering MHD generators, the electrical conductivity of a gas is a function of the density of free electrons and their mobility $[2,9,10]$. This is shown in Eq. (4), where $e$ is electron charge, $n_{e}$ is electron number density, and $\mu$ is electron mobility.

$\sigma=e n_{e} \mu$

Electron charge is a fundamental constant, and electron number density was determined by the combustion plasma model described in the preceding section. Electron mobility is a coefficient of proportionality between the electron drift velocity and electric field strength [12]. The electron mobility for a weakly ionized plasma, such as that of a seeded MHD combustion system, is given by Eq. (5) [12].

$\mu=\frac{4 \pi e}{3 m} \int_{0}^{\infty}\left[-\frac{d}{d v} f(v)\right]\left(\frac{v^{3}}{v_{t}(v)}\right) d v$

In Eq. (5), $v$ is electron velocity and $f(v)$ is the isotropic velocity distribution of electrons, which can be considered Maxwellian and is given by the Maxwell-Boltzmann distribution shown in Eq. (6) [12].

$f(v)=\sqrt{\left(\frac{m}{2 \pi k T}\right)^{3}} e^{-\frac{m v^{2}}{2 k T}}$

For simple implementation in Eq. (5), $d f(v) / d v$ can be computed analytically.

$\frac{d}{d v} f(v)=-\sqrt{\left(\frac{1}{2 \pi}\right)^{3}\left(\frac{m}{k T}\right)^{5}} v e^{-\frac{m v^{2}}{2 k T}}$

In Eq. (5-7), $m$ is electron mass, $k$ is Boltzmann's constant and T is bulk electron temperature. It is assumed that the bulk electron temperature is equal to gas temperature for a thermally ionized combustion plasma [2, 10, 12]. The Maxwell-Boltzmann distribution in Eq. (6) and Eq. (7) is written in terms of electron velocity. Electron velocity, temperature $\left(1 / 2 m_{e} v^{2} k_{b}^{-1}\right.$ in $\left.\mathrm{K}\right)$ and energy (kinetic energy: $1 / 2 m_{e} v^{2}$ in joules or electron-volts: $1 \mathrm{eV}=$ $1.602 \times 10^{-19} \mathrm{~J}$ ) can be easily converted between.

The parameter $v_{t}$ in Eq. (5) is the neutral species total collisional frequency, determined by Eq. (8) for a total of $\mathrm{N}$ species. For each species, $n_{i}$ is the number density and $Q_{i}$ is the relevant collisional cross-section (shown here as a function of electron velocity).

$v_{t}(v)=\sum_{i=1}^{N} v n_{i} Q_{i}(v) \quad E q .(8)$ 
Figure 2 shows the differentiated Maxwell-Boltzmann distribution, $d f(v) / d v$, as a function of electron velocity for the case of a $3000 \mathrm{~K}$ bulk gas temperature, overlaid with several species collisional cross-sections. The plotted range corresponds to approximately $0-2 \mathrm{eV}$ or $0-20000 \mathrm{~K}$. The electron velocity corresponding to the bulk gas temperature is identified as well as the general range of interest to MHD applications, which is approximately 0.13-0.3 eV or 1500-3500 K. It should be noted that the collisional cross-section data in Fig. 2 represent a subsection [13-19] of the data sources consulted to develop the final recommended correlations presented below.

Evaluation of the integral expression in Eq. (5) must be performed numerically if one considers $v_{t}(v)$, and is in general computationally expensive. However, the electron mobility expression may be significantly simplified if $v_{t}$ may be considered constant. For low-energy plasmas $(<1 \mathrm{eV})$ involving species typical for hydrocarbon combustion, this may be a reasonable assumption. In Fig. 2, it can be seen that many species exhibit little variation over the range of electron velocities relevant to MHD. However, for species such as $\mathrm{H}_{2} \mathrm{O}, \mathrm{OH}$, and potassium compounds (atomic potassium, $\mathrm{KOH}$ ), there does tend to be a fair amount of variation, especially at lower temperatures. To account for this variation to some degree, $Q_{i}$ is evaluated at the bulk gas temperature, allowing a value to be utilized within the region of greatest contribution by the Maxwell-Boltzmann integration.

Assuming $v_{t}=$ const., the combined form of Eq. (5) and Eq. (8) may be rewritten as shown in Eq. (9), where $\langle v\rangle$ is a relevant statistical velocity derived from the Maxwell-Boltzmann distribution.

$\mu=\frac{4 \pi e}{3 m}\left(\frac{1}{2 \pi}\right)^{3 / 2}\left(\frac{m}{k T}\right)^{5 / 2} \frac{1}{<v>\sum_{i=1}^{N} n_{i} Q_{i}} \int_{0}^{\infty} v^{4} e^{-\frac{m v^{2}}{2 k T}} d v$

As a result of this simplification, a closed-form expression for the integral in Eq. (9) exists, such that $\int_{0}^{\infty} v^{n} e^{-a v^{2}} d v=\frac{(2 k-1) ! !}{2^{k+1} a^{k}} \sqrt{\frac{\pi}{a}}$, where $n=2 k, k$ is an integer, and $a>0$. This results in a significant simplification of the electron mobility equation, shown in Eq. (10).

$\mu=\frac{e}{m<v>\sum_{i=1}^{N} n_{i} Q_{i}}$

The choice of a representative statistical velocity in Eq. 10 will directly affect the resulting electrical conductivity calculations. The Maxwell-Boltzmann mean speed, $(8 \mathrm{kT} / \pi \mathrm{m})^{1 / 2}$, has been used exclusively in this work as well as by Rosa [2, 10], who has presented an identical expression to Eq. (10) when describing electron-neutral collisions. Depending on how strongly $Q_{i}$ varies with electron velocity, there can be differences in calculated electrical conductivity between the full integration and simplified methods. On one hand, performing the full integration using Eq. (5) should provide the most accurate determination of electron mobility. However, this also places a great deal of emphasis on the accuracy of collisional cross-section data at very low energy levels. For seeded combustion plasmas, this may be particularly problematic since the collisional cross-sections increase significantly for $\mathrm{H}_{2} \mathrm{O}, \mathrm{OH}$, and potassium compounds (atomic potassium, $\mathrm{KOH}$ ) at lower temperatures.

As an example, Fig. 3 shows the difference between the electron mobility determined by the full integration method in Eq. (5) and the simplified method in Eq. (10), using the Maxwell-Boltzmann mean speed. Both utilize the same subset of collisional cross-section data shown in Fig. 2 and assume stoichiometric oxygen-methane combustion at constant temperature and pressure, with $1 \%$ atomic potassium by mass $\left(Y_{K}\right)$ seeding. It can be seen that $\sim 3000 \mathrm{~K}$, which is approximately the targeted temperature for the oxygen-methane MHD system, the two methods agree within $5 \%$. 
As temperatures and ion concentrations increase, electron-ion collisions must also be considered $[2,9,10]$. Rosa [10] presents several ways to include these effects, so-called mixture rules, which can allow neutral and ion contributions to be determined separately, leading to a final additive electrical conductivity.

One such additive conductivity expression, suggested by Lin et al. [11], is shown in Eq. (11). Here, $\sigma_{\text {en }}$ is the electrical conductivity due to electron-neutral collisions and $\sigma_{\mathrm{ei}}$ is due to electron-ion collisions.

$\frac{1}{\sigma}=\frac{1}{\sigma_{e n}}+\frac{1}{\sigma_{e i}}$

The electron-neutral contribution is determined by combining Eq. (4) and Eq. (10), as shown in Eq. (12) with <v> replaced by $(8 \mathrm{kT} / \pi \mathrm{m})^{1 / 2}$.

$\sigma_{e n}=\frac{e^{2} n_{e}}{m\left[\frac{k k T}{\pi m}\right]^{1 / 2} \sum_{i=1}^{N} n_{i} Q_{i}}$

Lin et al. [11] have proposed Eq. (13) for $\sigma_{\mathrm{ei}}$ following the Spitzer-Harm expression [10].

$\sigma_{e i}=1.975 \frac{n_{e} e^{2}}{\overline{m v_{e l}}}$

Here, $\overline{v_{e l}}=3.64 \times 10^{-6} n_{i}(\ln \Lambda) T^{-3 / 2}$ and $\Lambda=1.24 \times 10^{7}\left(T^{3} / n_{e}\right)$ (MKS units). Eq. (13) describes Coulomb scattering of electrons by ions, but does not consider electron-electron collisions or recombination effects. In general, electron scattering by ions contributes at most to $\sim 10 \%$ of the overall conductivity for all conditions examined in this work. It has been suggested in [20] that the Spitzer-Harm theory may have 20\% uncertainty at ionization levels representative of seeded oxygen-methane combustion plasmas. As such, uncertainty in the overall electrical conductivity due to the approach taken to represent electron-ion interactions may be on the order of $\sim 2 \%$, well within the measurement error of what limited experimental data sets presently exist. Rosa [10] notes that Eq. (11) is preferable to his more simplified mean free path expression and that additive conductivity is necessarily correct in the limits of weakly and fully ionized plasmas, yet there could be error at intermediate degrees of ionization. The recommended mixture rules and mobility simplifications are subject to change pending the release of improved validation data. The updated collisional cross-section data and preliminary model comparisons are discussed in detail in the sections following.

\section{Literature Survey of Collisional Cross-Section Data}

As discussed previously, determination of gas electrical conductivities relies on fundamental data which describe the collisional interactions between free electrons and other species present in the combustion products. Electron collisions with other species are elastic, inelastic or a total of both (also called effective). Depending on the particular species and electron energy level, inelastic contributions may be negligible such that elastic and effective collisional cross sections are nearly identical. However, for some species, such as $\mathrm{H}_{2} \mathrm{O}$ which has a low rotational excitation threshold [21], there may be a significant difference between the two. Seeded combustion products found in open-cycle MHD systems are generally considered to be thermal plasmas at thermodynamic equilibrium. As such, it is assumed that bulk gas and electron temperatures are equal and a uniform MaxwellBoltzmann velocity distribution is maintained $[2,9,10,17,22]$. Consequently, nonthermal electron transport processes are assumed to be negligible and elastic collisions dominate. Consistent with past works $[2,9,17]$, this has led to the use of the momentum transfer cross section (MTCS) to describe electron-neutral collisions. 
The likelihood an electron will interact in such a way is determined by the colliding species' MTCS. The higher the MTCS, the more likely an interaction, or collision. MTCS data can directly impact predictions of gas electrical conductivity. All species present within the combustion products have the potential to interact through momentum transfer with the free electrons formed through thermal ionization of the seed material. The probability that a neutral species will interact with the electrons increases with concentration. A neutral species which happens to have both a relatively high MTCS and a relatively high product gas concentration will interact with and slow the electrons the most.

Past publications $[2,9,17,23,24]$ have presented data and correlations for MTCS in the context of MHD power generation. However, these publications are now upwards of 50 years old, most included significant (or unstated) uncertainty (ex. $\pm 30 \%$ [9]), and in many cases applicability was limited. Most MTCS data in recent literature are not published with MHD power generation in mind; these publications are typically focused towards a general plasma physics audience. A meta-analysis of all available MTCS sources was performed and correlations for neutral (non-ion) chemical species of interest to open-cycle MHD systems are recommended.

In general, there are four categories that species may be placed in depending on their concentration in the combustion product gas, corresponding MTCS magnitude, and variation among sources.

1. Low Impact: These species have the lowest impact on resulting electrical conductivity calculations, minimizing the effect of variations in MTCS data. For the data in Table 5, this includes $\mathrm{H}_{,} \mathrm{H}_{2}, \mathrm{~N}, \mathrm{~N}_{2} \mathrm{O}$, NO, $\mathrm{O}, \mathrm{O}_{2}$, Ar. Results from electrical conductivity calculations differ by $<1 \%$ among all sources consulted.

2. Medium Impact: Despite having high product gas concentrations, these species have an overall low impact on electrical conductivity predictions due to low MTCS and generally low variation among sources. For the data in Table 5, this includes $\mathrm{CO}, \mathrm{CO}_{2}$, and $\mathrm{N}_{2}$. Results from electrical conductivity calculations differ by $<1 \%$ among all sources consulted.

3. Medium-High Impact: These species can have a significant impact on electrical conductivity calculations, and variations in MTCS data can notably affect the results. For the data in Table 5, this includes atomic potassium, $\mathrm{KOH}$, and $\mathrm{OH}$. Results from electrical conductivity calculations differ by up to $5 \%$ among all sources consulted for each species.

4. High Impact: These species have the largest impact on electrical conductivity calculations. Here, variations in MTCS data are prevalent and directly visible in the resulting electrical conductivity predictions. For the data in Table 5, this includes $\mathrm{H}_{2} \mathrm{O}$. Results from electrical conductivity calculations may differ by up to a factor of two depending on which MTCS data source is chosen.

For categories one and two, the selection of MTCS data source generally has a negligible impact on electrical conductivity calculations for open-cycle MHD power generation applications. As such, correlations for these species were developed by taking an average of all sources consulted (Table 5, far right column). In general, all sources for species in these categories are in fairly good agreement, with negligible differences between elastic and total MTCS (for data sets which include a mixture of both). Species falling within categories three and four, however, warrant additional discussion due to the significant impact that variations in MTCS data can have on the resulting electrical conductivity predictions. 


\subsection{Species of Importance to MHD}

\section{Atomic Potassium}

Momentum transfer collisional cross-sections for atomic potassium are among the largest of all species considered. However, the impact on conductivity with data set variation is reasonably low because it appears in the combustion product gases at very low concentration for practical seed levels. Three MTCS data set sources $[16,17,24]$ have been consulted for atomic potassium (Table 1). The data are in fairly close agreement between all three sources with the greatest differences located in the 0.2 to $0.25 \mathrm{eV}$ electron energy range. Here there is around a $12 \%$ difference between Itikawa and Bünde, and roughly a $19 \%$ difference between Itikawa and Spencer. Above $0.25 \mathrm{eV}$ electron energy, values from Itikawa and Bünde are within $0.1 \%$. A difference of around 4 to $6 \%$ is observable across the $0.13-0.3 \mathrm{eV}$ range between Spencer and Bünde.

Table 1. Atomic potassium MTCS data

Spencer and Phelps cite Moores and Norcross [25] for quantum mechanical theoretical calculation data between 0 and $5 \mathrm{eV}$, but from an earlier publication through private communication. The data are effective

Spencer MTCS. According to the authors, data below $1 \mathrm{eV}$ are calculations performed by Norcross while those above 1 (1976) $\mathrm{eV}$ are by Moores. The two agree between 0.5 and $1 \mathrm{eV}$. Spencer and Phelps also discuss earlier work by Karule

[17] [26] having good agreement with other experimental sources. The data presented should be closer to Itikawa [16] than the observed 4-6\% difference because both sources cite the same original data sets. There is no clear explanation for this difference so the conclusion is there may be some error.

Bünde et al. present data which derive from the work of Karule and Peterkop [26], but the conference publications are unavailable in online digital format. Experimental confirmation measurements of the Karule

Bünde and Peterkop work were performed by Collins and Visconti [27, 28] with statistical deviation between data

(1975) points for all sources less than $\pm 6 \%$. An atom-beam recoil technique to measure scattering angles (a type of

[24] crossed-beam experiment with observation made on scattered atoms instead of electrons) was used by both Collins and Visconti. The data are all effective MTCS. Karule and Peterkop use a two-state close-coupling approximation method for their theoretical calculations as described by Collins and Visconti.

Itikawa cites Moores [25], consisting of theoretical calculations for the higher electron energy range (above 0.5

Itikawa

(1978) $\mathrm{eV})$. The data are effective MTCS. Itikawa explains the data below $0.5 \mathrm{eV}$ were extrapolated from Moores by

[16] Norcross [29] using an unpublished method. Moores used a three-state close-coupling approximation and heavily compared this with the work of Karule and Peterkop [26], who use similar calculation methods in an another version of their work by Karule [30]. An excitation threshold was described by both authors in roughly the 1 to $2 \mathrm{eV}$ range. Moores' data is about 10\% higher than Karule below this threshold and drops lower above.

All three data sets reference the same general sources. The Itikawa set cites mostly theoretical sources while the Spencer and Bünde sets cite both theoretical and experimental sources. The Spencer data possibly include some error and only three data sets are compared, limiting the statistical relevance of the data. Electrical conductivity calculations vary by $<1 \%$ among sources. An average of the three data sets for use in open-cycle MHD combustion calculations is recommended at this time.

\section{Potassium Hydroxide ( $\mathrm{KOH})$}

Potassium hydroxide is both a possible seed source compound and a seed dissociation product in MHD systems. Momentum transfer collisional cross-sections for $\mathrm{KOH}$ are the largest found in seeded combustion product gases. Potassium hydroxide data set variation will have an impact on electrical conductivity calculations, but not as strongly as $\mathrm{H}_{2} \mathrm{O}$ because $\mathrm{KOH}$ appears at very low concentration. Two MTCS data set sources [17, 18] have been consulted for $\mathrm{KOH}$ (Table 2). The Spencer data is $57 \%$ higher than Collins data from 0.13-0.3 eV. 


\begin{tabular}{|c|c|}
\hline \multirow{3}{*}{$\begin{array}{l}\text { Collins } \\
(1979) \\
{[18]}\end{array}$} & $\begin{array}{l}\text { Collins provides an original source of theoretical MTCS data. The data are considered elastic. The authors } \\
\text { used close-coupling calculations, shown in Eq. (14), and describe this method as being good for determining } \\
\text { MTCS data specifically for alkali species such as } \mathrm{KOH} \text {. It is claimed that this method is more accurate than the } \\
\text { Born approximation method used by Spencer [17] for } \mathrm{KOH} \text {. }\end{array}$ \\
\hline & $Q_{\text {KоH }}=\frac{\beta C}{2 k_{B} T}$ \\
\hline & $\begin{array}{l}\text { Here, } T \text { is the electron temperature, described by the formula, } 2 E / 3 k \text {, where } \mathrm{E} \text { is the electron energy, } C \text { is a } \\
\text { fitting parameter, } \beta \text { is a conversion factor from the units of } C \text { to CGS. The fitting parameter } C \text { was assigned a } \\
\text { value of } 364.8 \text { by the authors. This value is dependent on the dipole moment of } \mathrm{KOH} \text { through } C=110 D \text {. The } \\
\text { authors have thus used a } \mathrm{KOH} \text { dipole moment of around } 3.3 \mathrm{D} \text {, which is about half of more recently published } \\
\text { values. Two authors give newer } \mathrm{KOH} \text { dipole moment values of } 7.415 \pm 0.002 \mathrm{D} \text { [31] and 7.386 } \pm 0.001 \mathrm{D} \text { [32]. }\end{array}$ \\
\hline \multirow{3}{*}{$\begin{array}{l}\text { Spencer } \\
\text { (1976) } \\
{[17]}\end{array}$} & $\begin{array}{l}\text { Spencer and Phelps describe their own theoretical calculations for KOH MTCS data. The cross-sections are } \\
\text { effective. The authors utilized Eq. (15), which is based on the Born approximation and } 60 \% \text { of a formula by } \\
\text { Altschuler [33] (the } 60 \% \text { approximation is based on other literature results described and accounts for higher } \\
\text { polarity associated with } \mathrm{KOH} \text { ). }\end{array}$ \\
\hline & $Q_{K O H}=\frac{8 \pi}{3}\left(\frac{2 \pi D e}{h v}\right)^{2}$ \\
\hline & $\begin{array}{l}\text { Here, } v \text { is the electron speed, estimated by Maxwell-Boltzmann mean speed, }(8 \mathrm{kT} / \pi \mathrm{m})^{1 / 2} \text {, where } T \text { is the } \\
\text { electron temperature, } h \text { is Planck's constant, and } D \text { is the dipole moment. Spencer and Phelps estimate the } \\
\text { dipole moment of } \mathrm{KOH} \text { using the dipole moments of potassium fluoride and hydroxyl radicals: } D(\mathrm{KOH})= \\
D(\mathrm{KF})-\frac{1}{2} D(\mathrm{OH})=7.77 \pm 0.7 \mathrm{D} \text { with } D(\mathrm{KF})=8.60 \& D(\mathrm{OH})=1.66 \text {. As explained previously, larger } \\
\text { values for the } \mathrm{KOH} \text { dipole moment have been published recently. }\end{array}$ \\
\hline
\end{tabular}

Both data sets derive from completely theoretical calculations, with Collins data being considered elastic and Spencer being considered effective. There are possible inaccuracies as only two data sets are compared. The two sets use different approaches, with possible improved accuracy being exhibited by Collins for alkali species such as $\mathrm{KOH}$. The original Spencer data is $57 \%$ higher than the original Collins data. However, when both of these data sets are recalculated with newly published $\mathrm{KOH}$ dipole moments, the Spencer data decreases by $9-11 \%$ and the Collins data more than doubles, bringing it within $5 \%$ of Spencer.

Electrical conductivity calculations using both original sets of data and both recalculated sets of data are within $5 \%$ across the $0.13-0.3 \mathrm{eV}$ range. The Collins data with a substitution of a modern $\mathrm{KOH}$ dipole moment (average of $[31,32])$ is recommended for use in open-cycle MHD combustion calculations due to a more well defined calculation method which relies on fewer estimations and is specifically focused on elastic scattering of electrons by highly polar molecules. This recommendation is subject to change if any new literature appears concerning $\mathrm{KOH}$, specifically any experimental work.

\section{Water $\left(\mathrm{H}_{2} \mathrm{O}\right)$}

Water is a primary combustion product and is very common in open-cycle MHD systems. MTCS data for $\mathrm{H}_{2} \mathrm{O}$ are among the largest found in open-cycle MHD product gases, but are smaller than those of $\mathrm{KOH}$ and atomic potassium. Water data set variation will have a strong impact on conductivity calculations because of the MTCS magnitude and because $\mathrm{H}_{2} \mathrm{O}$ appears in the MHD combustion product gases at very high concentration. Therefore, $\mathrm{H}_{2} \mathrm{O}$ MTCS literature is highly important to analyze in detail. Twelve MTCS data set sources [14, 16, 17, 24, 34-40] have been consulted for $\mathrm{H}_{2} \mathrm{O}$ (Table 3a-d). This includes two relevant online databases: the LXCAT Plasma Data Exchange (PDE) [35, 39-41], a collection of data sets useful to the low-temperature plasma 
community, and the JILA scientific publications database [38], developed through a joint effort between the University of Colorado at Boulder and the National Institute of Standards and Technology (NIST).

The MTCS data for all sources considered can be roughly separated into four energy range groups within the 0.13-0.3 eV energy range based on their magnitude. These groups may be described as low range (Table 3a), middle range (Table $3 \mathrm{~b}$ ), high range (Table $3 \mathrm{c}$ ), and very high range (Table $3 \mathrm{~d}$ ). Large differences between data sets are apparent and these differences are expected to greatly vary any electrical conductivity calculations depending on which data set is used. The average of the data across $0.13-0.3 \mathrm{eV}$ in the middle range is about 150-172.5\% higher than the average of the data across the same energies in the low range. Additionally, the very high range is about $487.5-515 \%$ higher than the average of the data across $0.13-0.3 \mathrm{eV}$ in the low range.

Table 3a. $\mathrm{H}_{2} \mathrm{O}$ MTCS data (low range)

Itikawa and Mason present elastic $\mathrm{H}_{2} \mathrm{O}$ MTCS data from the swarm experiment analysis work of Yousfi
and Benabdessadok [21]. The data is a fairly new source compared to the other swarm sources described
later in this section. Yousfi and Benabdessadok make a comparison to another source of $\mathrm{H}_{2} \mathrm{O}$ MTCS by
Pack et al. [42] and note the data is higher than their recommended set. The authors explain this
discrepancy could be because Pack et al. did not account for rotational excitation, which has a very low
threshold in $\mathrm{H}_{2} \mathrm{O}$. As a result, they suggest that the data generated by Pack et al. may rather be
considered as total cross-section data. Itikawa and Mason compare the Yousfi and Benabdessadok elastic
MTCS data to the higher electron energy (above $3 \mathrm{eV}$ ) beam experiment work of Cho et al. [43] and
explain the two sets are in good agreement.


Table 3b. $\mathrm{H}_{2} \mathrm{O}$ MTCS data (middle range)

\begin{tabular}{|c|c|}
\hline $\begin{array}{l}\text { Hayashi } \\
\text { (2003) [36] }\end{array}$ & $\begin{array}{l}\text { Hayashi presents a bibliography publication listing various } \mathrm{H}_{2} \mathrm{O} \text { cross-section-related literature. The } \\
\text { author includes an insert with a description and presentation of MTCS data calculated using the } \\
\text { theoretical methods of Parker and Lowke }[44,45] \text {. Parker and Lowke discuss using the unpublished } \\
\text { theoretical MTCS work of Cohen and Phelps [46] for some of their demonstration calculations. The Cohen } \\
\text { and Phelps MTCS data are not mentioned by Hayashi. }\end{array}$ \\
\hline $\begin{array}{l}\text { Mark (1995) } \\
\text { [37] }\end{array}$ & $\begin{array}{l}\text { Mark et al. obtained their data from both Shimamura [47] and Hayashi [48] and state the two sources are } \\
\text { identical. Hayashi [48] is discussed in their own } 2003 \text { bibliography publication [36], where it is claimed } \\
\text { that the data were developed from that of Parker and Lowke [44, 45]. The Hayashi source [41, 48] cited } \\
\text { by Mark et al. contains MTCS for } \mathrm{H}_{2} \mathrm{O} \text { which are indicated to be elastic based on the differential cross- } \\
\text { section used to calculate them }\end{array}$ \\
\hline $\begin{array}{l}\text { Itikawa } \\
\text { (1978) [16] }\end{array}$ & $\begin{array}{l}\text { Itikawa acquires the data below } 0.45 \mathrm{eV} \text { from the work of Pack et al. [42], which had been described } \\
\text { previously by Yousfi and Benabdessadok [21] as total cross-sections. Itikawa describes the Pack et al. data } \\
\text { as deriving from swarm experiments. }\end{array}$ \\
\hline $\begin{array}{l}\text { Bünde } \\
\text { (1975) [24] }\end{array}$ & $\begin{array}{l}\text { Bünde includes data in the MHD range of interest from two original sources. The first original source by } \\
\text { Bailay and Duncanson [49] is a relatively old publication containing what could be described as } \\
\text { experimental swarm data for the } 0.15 \text { to } 2 \mathrm{eV} \text { range, but caution "these measurements are doubted" } \\
\text { without providing additional detail. The second original source, by Chambers and Tuba [50], contains data } \\
\text { for the } 0.0005 \text { to } 6 \mathrm{eV} \text { range. However this paper has proven to be unavailable so far in any online } \\
\text { database or library. Whether the data presented by Bünde et al. are elastic or effective is not stated by } \\
\text { the authors. }\end{array}$ \\
\hline $\begin{array}{l}\text { LXCat PDE: } \\
\text { Hayashi } \\
\text { Database- } \\
\text { elastic [41] }\end{array}$ & $\begin{array}{l}\text { The data are from a book article by Hayashi [51]. Hayashi gives an explicit warning, noted in the database, } \\
\text { to not use this data set for Boltzmann calculations because it does not consider rotational cross-sections } \\
\text { and cites many sources, including some works previously described in this section }[17,42,52-54] \text {. }\end{array}$ \\
\hline
\end{tabular}

Table 3c. $\mathrm{H}_{2} \mathrm{O}$ MTCS data (high range)

Spencer and Phelps explain that the lower-end electron energy $\mathrm{H}_{2} \mathrm{O}$ MTCS data are derived from the unpublished work of Cohen and Phelps [46] based on electron transport data work by Pack et al. [42] and others $[52,54,55]$ from the 1960s. The Cohen and Phelps work was discussed previously as being used for demonstration calculations in the Parker and Lowke sources [44, 45] referenced in Hayashi [36]. There is no clear explanation as to why Hayashi [36] and Spencer differ so much in the 0.2 to $0.4 \mathrm{eV}$ Spencer range. However, Spencer and Phelps note more recent electron transport data [53], compared with the (1976) [17] electron transport work they used from the 1960s, show a noteworthy reduction in MTCS values compared to the unpublished Cohen and Phelps work. Spencer and Phelps cite another work by Schlumbohm [56] and give the following explanation: "One source of concern is the validity of the spherical harmonic expansion technique for the solution of the Boltzmann equation used to analyze the nonthermal electron transport data for electrons in gases, such as $\mathrm{H}_{2} \mathrm{O}$, in which inelastic (rotational excitation) collision cross-sections exceed elastic cross-sections".

JILA Database The same data are presented in [17].

LXCat PDE:

Phelps

Database-

The same data are presented in [38].

effective [39]

Table 3d. $\mathrm{H}_{2} \mathrm{O}$ MTCS data (very high range) 
LXCat PDE: $\quad$ The data contains effective MTCS data, but no original source is cited other than indicating the data was Morgan compiled by an author named W.L. Morgan. The Morgan database provides a similar note to the Database- Hayashi database explaining not use this cross-section set for Boltzmann calculations because it does effective [40] not consider rotational cross-sections.

There are many discrepancies between the twelve sources. In the application of collisional cross section data, the appropriate type to use will depend on the model and ultimately the purpose of its use. In this case, the conductivity model is based on past work $[2,9,17]$ which calls for the use of MTCS data, as opposed to total cross section data. However, as has been mentioned, the differentiation between reported total, elastic and MTCS data can be incomplete and unclear in the source. Based on our review of these sources, the current recommendation is to use the newer MTCS data set from Itikawa (2005), from the low range. As such, we might expect our calculated conductivity values to be higher than legacy reported calculations. Nonetheless, and presented below, use of the newer MTCS data for $\mathrm{H}_{2} \mathrm{O}$ along with the modeling methodology described above has resulted in reasonably favorable comparisons to the limited experimental electrical conductivity data available. Still, the appropriate model and data to use when considering the impact of electron- $\mathrm{H}_{2} \mathrm{O}$ collisions on electrical conductivity for MHD applications is subject to change based on further analysis or experiments. Although an uncertainty analysis is not presented with this work, we expect the uncertainty in $\mathrm{H}_{2} \mathrm{O}$ collisional cross section data to be one of the most important sources in conductivity calculations at this time.

\section{Hydroxyl Radical (OH)}

The hydroxyl radical is an important dissociation species present in open-cycle MHD systems. Hydroxyl radicals are formed through dissociation of $\mathrm{H}_{2} \mathrm{O}$ and $\mathrm{KOH}$ molecules at high temperatures. Hydroxyl radicals have a fairly high MTCS, but appear in low concentration in most combustion systems. As such, OH MTCS data source variation can have an impact on electrical conductivity calculations, but again, not as strongly as $\mathrm{H}_{2} \mathrm{O}$. Two MTCS data set sources $[17,24]$ have been consulted for $\mathrm{OH}$ (Table 4). There is an approximately 80 to $83 \%$ difference between the Spencer and Bünde data across the 0.13-0.3 eV range.

Table 4. OH MTCS data

Spencer and Phelps describe their own theoretical calculations for OH MTCS data. The authors Eq. (15) to determine MTCS data first for $\mathrm{H}_{2} \mathrm{O}$ (using $\mathrm{H}_{2} \mathrm{O}$ dipole moment), and then determine values for $\mathrm{OH}$ based on Eq. (16).

Spencer

$$
Q_{\mathrm{OH}}=\left(\frac{D_{\mathrm{OH}}}{D_{\mathrm{H}_{2} \mathrm{O}}}\right)^{2} Q_{\mathrm{H}_{2} \mathrm{O}}
$$

(1976)

Here, $D$ is the dipole moment, where $D_{O H}=1.66$ and $D_{H_{2} O}=1.85$ (also implemented in Eq. (15)). The authors give no information on the derivation of Eq. (16). As was discussed previously, the Spencer and Phelps $\mathrm{H}_{2} \mathrm{O}$ cross-section calculations are called into question by other authors, which implies these $\mathrm{OH}$ crosssections may also be questionable. The authors state no experimental work was available for $\mathrm{OH}$ at the time of publication and give no indication as to whether the resulting cross-sections are considered elastic or effective.

Bünde Bünde et al. provide data for the 0.0005 to $6 \mathrm{eV}$ range from an unconfirmed paper by Chambers and Tuba (1975) [50], which has proven to be unavailable so far. Whether the data is elastic or effective is not discussed by the authors.

Electrical conductivity calculations exhibit a 1-5\% difference when utilizing the Spencer and Bünde data sets. There are some uncertainties associated with both data sets. The calculation method used by Spencer relies on their own $\mathrm{H}_{2} \mathrm{O}$ data to generate values for $\mathrm{OH}$, which may be questionable, leaving the $\mathrm{OH}$ results uncertain. The original source of OH MTCS data used by Bünde is unavailable, thus their data is not recommended until the 
source can be found and analyzed. As a result, it is recommended to use Eq. (16), given by Spencer, to calculate $\mathrm{OH}$ MTCS in conjunction with the updated $\mathrm{H}_{2} \mathrm{O}$ data $\left(\mathrm{Q}_{\mathrm{H2O}}\right)$ from Itikawa (2005) [14]. This recommendation is subject to change if any new literature appears with stronger data for $\mathrm{OH}$.

\subsection{Recommended MTCS Correlations}

As a result of the literature survey described in the previous section, correlations were determined, as a function of temperature, for each of the fifteen species considered. Table 5 shows polynomial coefficients, up to $3^{\text {rd }}$ order, along with the specific data sources used to develop each correlation, which are in accordance with the species-specific discussions above. All recommendations are based on available data and subject to change upon release of new MTCS information.

Table 5. Recommended MTCS correlations, $\operatorname{MTCS}\left(m^{2}\right)=A T^{3}+B T^{2}+C T+D$, where $T=$ gas temperature $(K)$, all correlations applicable for $\mathrm{T}=1500-3500 \mathrm{~K}(0.13-0.3 \mathrm{eV})$

\begin{tabular}{|c|c|c|c|c|c|}
\hline & $A$ & $B$ & C & $D$ & Sources \\
\hline $\mathrm{Ar}$ & $-3.345 E-31$ & $4.052 E-27$ & $-1.454 \mathrm{E}-23$ & $1.715 \mathrm{E}-20$ & {$[16,17,37-39,41,57-64]$} \\
\hline $\mathrm{CO}$ & & & $1.913 \mathrm{E}-23$ & 5.523E-20 & {$[16,17,24,34,38-40]$} \\
\hline $\mathrm{CO}_{2}$ & & $3.148 E-26$ & $-2.871 \mathrm{E}-22$ & 7.982E-19 & {$[13,16,17,24,34,35,37-39,41,62,65]$} \\
\hline $\mathbf{H}$ & & & $-5.266 \mathrm{E}-23$ & $5.836 \mathrm{E}-19$ & {$[15,17,24,61,62]$} \\
\hline $\mathrm{H}_{2}$ & & $-6.578 E-28$ & 1.287E-23 & $9.410 \mathrm{E}-20$ & {$[16,17,24,34,35,37-40,58,61,66]$} \\
\hline $\mathrm{H}_{2} \mathrm{O}$ & & $2.533 \mathrm{E}-25$ & $-1.842 \mathrm{E}-21$ & 4.066E-18 & [14] \\
\hline $\mathbf{K}$ & & 4.291E-25 & $-3.434 \mathrm{E}-21$ & $9.582 \mathrm{E}-18$ & {$[16,17,24]$} \\
\hline KOH & & $1.274 \mathrm{E}-24$ & $-9.870 \mathrm{E}-21$ & $2.465 \mathrm{E}-17$ & {$[18,31,32]$} \\
\hline $\mathbf{N}$ & & $-3.440 E-28$ & $4.716 \mathrm{E}-24$ & $9.245 E-21$ & {$[40,67]$} \\
\hline $\mathbf{N}_{\mathbf{2}}$ & & $-1.411 E-27$ & $1.836 \mathrm{E}-23$ & 4.404E-20 & {$[15,17,19,35,37-40,58,65,67,68]$} \\
\hline $\mathrm{N}_{2} \mathrm{O}$ & & $1.452 \mathrm{E}-26$ & $-1.073 \mathrm{E}-22$ & 2.340E-19 & [41] \\
\hline NO & & 1.219E-26 & $-3.286 \mathrm{E}-23$ & 5.789E-20 & {$[15,17,38-40,69]$} \\
\hline $\mathbf{0}$ & & $-2.520 \mathrm{E}-28$ & $3.223 E-24$ & 2.709E-20 & {$[16,17,24,40,70]$} \\
\hline $\mathbf{O}_{2}$ & & & $6.473 E-24$ & $2.569 E-20$ & {$[15,17,24,34,35,37,38,40,41,60,67,71,72]$} \\
\hline $\mathrm{OH}$ & & 5.359E-26 & $-3.994 \mathrm{E}-22$ & $9.652 \mathrm{E}-19$ & {$[14,17]$} \\
\hline
\end{tabular}

Table 6 shows the resulting MTCS for each species, determined by evaluating the correlations in Table 5 at a temperature of $3000 \mathrm{~K}$, which is representative of stoichiometric oxygen-methane combustion (neglecting heat loss). In addition, MTCS data published in four common legacy publications $[2,9,17,24]$ were evaluated at 3000 $\mathrm{K}$ in order to highlight similarities and differences. This provides a quantitative understanding of the relative MTCS magnitudes for the species considered and highlights the level of significance for species such as atomic potassium, $\mathrm{KOH}, \mathrm{H}_{2} \mathrm{O}$, and $\mathrm{OH}$. Additionally, the degree of variation between the selected legacy publications can be seen, which demonstrates the importance of improved MTCS consistency for accurate prediction of gas electrical conductivities in open-cycle MHD systems. 
Table 6. MTCS comparison among legacy MHD-oriented sources $\left(\mathrm{m}^{2} \times 10^{20}\right.$, evaluated at $\left.3000 \mathrm{~K}\right)$

\begin{tabular}{rccccc}
\hline & from Table 5 & Frost [9] & Rosa [2] & Spencer [17] & Bünde [24] \\
\hline $\mathbf{A r}$ & 0.10 & -- & 0.35 & 0.09 & \\
$\mathbf{C O}$ & 11.26 & 7.80 & 8.00 & 11.20 & 11.00 \\
$\mathbf{C O}_{\mathbf{2}}$ & 22.02 & 14.62 & 15.00 & 25.00 & 25.00 \\
$\mathbf{H}$ & 42.57 & 58.81 & & 36.00 & 67.00 \\
$\mathbf{H}_{\mathbf{2}}$ & 12.68 & 12.90 & 13.80 & 12.50 & 12.90 \\
$\mathbf{H}_{\mathbf{2}} \mathbf{O}$ & 30.96 & 65.20 & 75.00 & 124.00 & 82.50 \\
$\mathbf{K}$ & 314.35 & 530.51 & 400.00 & 313.00 & 329.00 \\
$\mathbf{K O H}$ & 651.51 & -- & -- & 720.00 & -- \\
$\mathbf{N}$ & 2.03 & -- & 18.00 & -- & -- \\
$\mathbf{N}_{\mathbf{2}}$ & 8.64 & 10.29 & 6.50 & 8.50 & -- \\
$\mathbf{N}_{\mathbf{2}} \mathbf{O}$ & 4.28 & -- & -- & -- & -- \\
$\mathbf{N O}$ & 6.90 & -- & -- & 7.00 & -- \\
$\mathbf{O}$ & 3.45 & 9.27 & 20.00 & 4.92 & 5.40 \\
$\mathbf{O}_{2}$ & 1.85 & 4.64 & 3.00 & 5.30 & 4.75 \\
$\mathbf{O H}$ & 24.93 & 52.81 & -- & 100.00 & 54.20 \\
\hline
\end{tabular}

\section{Model Validation and Review of Experimental Validation Data}

In order to validate the updated MTCS data and overall modeling approach, it was desired to compare calculated gas electrical conductivities to published experimental data. However, finding high quality experimental electrical conductivity data is challenging; especially when targeting oxy-combustion systems. While this publication is not meant to focus on experimental aspects of determining gas electrical conductivities, an understanding of the challenges associated with making reliable measurements is warranted. First, directly measuring the electrical conductivity of a gas or flame is, by nature, an intrusive measurement. A probe (ex. Langmuir, radio frequency (RF) probe) is inserted into the flame in order to infer the electrical conductivity of the gas. Significant uncertainty may be introduced due to flow perturbations caused by the probe, heating and erosion of the probe, and determination of a suitable and stable probe calibration [73].

Second, in order to have a meaningful value of electrical conductivity, the seed concentration and gas temperature must be accurately known. Depending on the experimental configuration, these values may be determined in-situ using spectroscopic methods or may be stated from general process measurements. As a result, generating reliable experimental electrical conductivity data requires performing three independent measurements, with a high degree of accuracy. Three sources of experimental gas electrical conductivity data in oxy-combustion systems were identified, all of which are from the 1970s and 1980s.

Two publications from the same group, authored by Sodha et al. [23] and Naidu et al. [74] present limited experimental electrical conductivity data for oxygen-acetylene and oxygen-acetylene-LPG (liquid petroleum gas) systems, respectively. Both were seeded with liquid solutions of $\mathrm{K}_{2} \mathrm{CO}_{3}$ and seed rate was determined by the liquid flow rate, though no uncertainty was provided. Both publications utilized a Langmuir double probe made of tungsten in order to determine the gas electrical conductivity. It was stated that a calibration factor, relating the electrical response to probe geometry, was determined by inserting the probe into a standard solution of $\mathrm{CuSO}_{4}$. The stated uncertainty of electrical conductivity measurement was $+/-10 \%$. Temperatures were determined by using an optical pyrometer directed at the tungsten probe tips within the gas stream and corrected for material emissivity. An uncertainty of $+/-50 \mathrm{~K}$ was stated. 
When examining the published data, there are some concerns; particularly with regards to the stated gas temperatures. First, for various seed rates or fuel $\mathrm{C} / \mathrm{H}$ ratios ([74], via acetylene-LPG mixture), a constant temperature is reported. This should not be expected, since as seed level increases, so does the accompanying water ballast, which will in turn reduce gas temperatures. And similarly, one would expect variation of $\mathrm{C} / \mathrm{H}$ ratio to cause a perceivable change in gas temperature due to variation in effective fuel heating value. Additionally, there are inconsistencies in how the seed level is specified throughout both publications, with no explicitly defined convention. Because of these inconsistencies, the data sets by Sodha and Naidu are not ideal for model validation.

Another publication which presents well-defined experimental electrical conductivity data for potassium-seeded oxy-combustion systems is that of Dixit et al. [73]. Here, the authors present electrical conductivity and temperature data for stoichiometric oxygen-LPG combustion, seeded with liquid $\mathrm{K}_{2} \mathrm{CO}_{3}$ solution. For model comparisons, LPG was simulated as a 50/50 mixture of butane/propane, and combustion and ionization calculations were run assuming constant temperature and pressure, using the published best-fit temperature measurement data. Because temperature was fixed and the $\mathrm{C} / \mathrm{H}$ ratio of butane and propane is similar, the exact LPG composition did not significantly impact the resulting product gas composition and electrical conductivity.

Seed concentration was determined by the liquid $\mathrm{K}_{2} \mathrm{CO}_{3}$ solution flow rate to the spraying apparatus, however no in-situ measurements of potassium atom concentration are provided. Gas temperatures were measured spectroscopically, using the sodium line reversal method. A detailed uncertainty analysis is presented, taking into account the error associated with making a line-of-sight measurement over the width of the duct, as well as lamp calibration error, lamp current measurement error, and error in the determination of the line reversal conditions. This resulted in a total temperature error of $+/-20 \mathrm{~K}$ at $2500 \mathrm{~K}$ and $600 \mathrm{~nm}$. Electrical conductivities were measured using an RF Q probe. Here, the change in inductance of a coil inserted into the flame within a cylindrical probe can be related directly to the electrical conductivity of the surrounding medium. Similar to [23, 74], the probe was calibrated by insertion into solutions of known electrical conductivity. The uncertainty analysis considered flow disturbance, probe heating, probe ablation, and calibration error, resulting in a total measurement uncertainty of $\sim 20 \%$. Figure 4 shows a comparison of electrical conductivities published by Dixit et al., as a function of seed rate (specified as mass fraction of atomic potassium, $\mathrm{Y}_{\mathrm{K}}$ ), along with those computed using the approach described above and updated MTCS data from Table 5. For reference, the temperatures reported by Dixit et al. are also presented on a secondary axis, along with error bars for all measured data and the best-fit curves plotted in [73]. In general, the model results compare well with the experimental data, albeit slightly high for lower seed levels when run at the published temperature conditions.

One final experimental electrical conductivity data set was located in a publication by Rosa [2], republished from work by Brogan [22]. Here, experimental electrical conductivity data are presented as a function of measured gas temperature for oxygen-JP4 (jet-fuel) combustion, along with predictions from a model developed by Brogan. Here, JP4 (50/50 gasoline/kerosene) was simulated as a mixture of jet-A and iso-octane. In the appendix of [22], MTCS data utilized by Brogan are shown, which are similar to those by Rosa utilized for the comparisons in Table 6.

Specific details are lacking in [22] as pertains to the diagnostic methods, however another legacy report by the Avco-Everett Research Laboratory [75] was found which contains additional information. It was stated in [75] that temperatures at the facility were determined optically by the sodium line-reversal method. Both publications [22, 75] describe electrical conductivity data as being determined by the current-voltage 
characteristics obtained between a pair of electrodes positioned on either side of the combustion duct. Unfortunately no uncertainty estimates are provided.

A comparison between the data published by Brogan along with model predictions utilizing updated MTCS data from Table 5 can be seen in Fig. 5 as a function of temperature for $1 \% Y_{K}$. It can be seen that overall good agreement is achieved, with model predictions being slightly low relative to experimental data points. In addition, the model predictions by Brogan are included, shown as a dashed line. Brogan indicated in [22] that such close agreement between model and experimental data was partially fortuitous.

In summary, model predictions utilizing the updated MTCS data appear slightly high relative to one experimental data source (Dixit et al. [73]) and low relative to another (Brogan [22]), highlighting the need for more well defined validation data sets. Still, it serves as an initial basis for evaluating applicability of the updated MTCS data. A more comprehensive comparison will be published at a later date pending the results of an ongoing experimental effort at NETL to make detailed electrical conductivity measurements under controlled conditions.

\section{Parametric Study of the Modern Oxy-Methane MHD Combustion System}

A parametric study was performed in order to demonstrate applicability of the model and updated MTCS data in the context of modern, open-cycle oxy-combustion MHD systems. In addition, comparisons are made to legacy approaches, which typically implemented air-fired combustion and high levels of preheat. First, the combustion and ionization model was run under conditions of constant enthalpy and pressure, in order to determine the equilibrium gas composition and temperature. This may be considered an upper limit for electrical conductivities within an MHD channel due to heat losses and finite rate kinetics. This was performed for the cases of oxygen-methane without preheat and air-methane with $1500 \mathrm{~K}$ preheat.

The oxy-combustion case was run with an initial reactant temperature of $400 \mathrm{~K}$ to ensure water vapor is in gas phase. As a result, gas temperatures, electron concentrations, and electrical conductivities may be slightly elevated relative to a practical liquid $\mathrm{K}_{2} \mathrm{CO}_{3}$ fed system and could correspond more closely to a system that implements $\mathrm{K}_{2} \mathrm{CO}_{3}$ powder directly [76]. Because oxygen separation processes tend to be expensive, all cases considered here utilize an equivalence ratio of one. Multiple $\mathrm{K}_{2} \mathrm{CO}_{3}$ seed levels were considered. Maintaining conventions of legacy MHD publications [2, 3, 9, 23, 73], the seed level is specified as either mass fraction atomic potassium in reactants, $\mathrm{Y}_{\mathrm{K}}$, or as a mass ratio of atomic potassium to fuel, $\mathrm{m}_{\mathrm{K}} / \mathrm{m}_{\mathrm{CH} 4}$. Seed solution concentration was fixed at $50 \%$ by mass $\mathrm{K}_{2} \mathrm{CO}_{3}$ in water.

Figure 6 shows the product gas molar composition and resulting adiabatic flame temperature for $1 \% Y_{K}$, for the cases of oxy-combustion and air-fired combustion with preheat. Legacy publications $[2,3,9,23,73]$ have suggested optimal seed levels of around 1-2\% atomic potassium, by mass, in practice, for open-cycle, air-fired MHD systems. It can be seen that the air-fired case, despite a high level of preheat, exhibits significantly lower ion and free electron concentration. This is primarily a result of decreased bulk gas temperatures, which drive the thermal ionization of atomic potassium. This will directly affect electrical conductivity and MHD power generation. For reference, without preheat, the air-fired case would produce an adiabatic flame temperature of $2239 \mathrm{~K}$. While Fig. 6 shows a near 1:1 relationship between $\mathrm{K}+$ ions and free electrons, a small fraction of electrons are consumed by $\mathrm{OH}$ or $\mathrm{O}$ radicals to form $\mathrm{OH}^{-}$and $\mathrm{O}^{-}$, respectively. This equates to less than $10 \%$ of available free electrons, even at the highest gas temperatures. For the air-fired case, very few $\mathrm{OH}^{-}$and $\mathrm{O}^{-}$ions are formed, a result of the reduced gas temperature and availability of nitrogen species to consume radicals. It is important to note, however, that electron consumption by $\mathrm{OH}$ and $\mathrm{O}$ radicals tends to increase with increasing pressure, which may be significant in a practical MHD channel being operated at elevated pressure [76]. 
Next, the compositions in Fig. 6 were converted to number densities and along with the MTCS data presented in Table 5, individual species average collisional frequencies were determined. Here, each species collisional frequency was determined according to Eq. (17), which represents the individual components of the summation in Eq. (8). Similar to Eq. (10), <v> is the electron velocity, estimated as the Maxwell-Boltzmann mean speed, $(8 k T / \pi m)^{1 / 2}$, evaluated at the corresponding gas temperature.

$v_{t_{i}}=\langle v\rangle n_{i} Q_{i}$

Figure 7 shows the collisional frequencies to more accurately illustrate the relative importance of each species for the oxy-combustion and air-fired with preheat cases compared to only considering MTCS magnitude. This further demonstrates the fact that species which have both a high product gas composition and MTCS magnitude tend to contribute most to the resulting electrical conductivity. Of particular interest is the increased significance of $\mathrm{H}_{2} \mathrm{O}$ and $\mathrm{OH}$ species in the oxy-combustion case.

The quantity of seed material introduced into the combustor must be carefully optimized in open-cycle MHD systems in order for overall system economics to be favorable. Generally speaking, increasing seed level will increase ion and free electron concentration, until the water ballast accompanying the potassium seed becomes significant enough to cause bulk temperature reductions due to energy lost to latent heat. In addition, for practical systems, the length and time scales associated with water evaporation, $\mathrm{K}_{2} \mathrm{CO}_{3}$ decomposition and atomic potassium ionization must be considered, especially at high seed levels.

Figure 8 (a) shows electron concentration as a function of seed level for $0.1-10 \% Y_{k}$, for the oxy-combustion and air-fired combustion with preheat cases. It can be clearly seen that the un-diluted oxy-combustion case produces significantly higher electron concentrations, primarily due to increased gas temperatures. Peak electron production is near $4 \% \mathrm{Y}_{\mathrm{K}}$ for air-fired combustion with preheat while for oxy-combustion the peak is located near $6 \%$. However, determining optimal seeding for the air-fired and oxy-combustion cases using the seed level convention in Fig. 8 (a) can be misleading because the total reactant mass is not constant. Since seed level is specified here as total mass fraction, the mass of seed material introduced varies with dilution (i.e. $\mathrm{N}_{2}$ in air).

By examining the same data with seed level specified as the mass ratio of atomic potassium to fuel, which is more logical for this comparison, the effects of varying reactant mass due to dilution are removed. Electron concentrations and temperatures using this convention can be seen in Fig. 8 (b), up to an atomic potassium to fuel mass ratio of one. Here, the $4 \% Y_{K}$ peak for the air-fired case translates to $\sim 0.8 \mathrm{~m}_{\mathrm{K}} / \mathrm{m}_{\mathrm{CH} 4}$, while for oxycombustion, the $6 \% \mathrm{Y}_{\mathrm{K}}$ peak corresponds to $\sim 0.35 \mathrm{~m}_{\mathrm{K}} / \mathrm{m}_{\mathrm{CH} 4}$. This implies that the optimal seed level may be significantly reduced in the oxy-combustion case; however, future work is needed to determine practical seed limits for these systems.

The product compositions and adiabatic flame temperatures presented above were used as inputs to the electrical conductivity model, along with the updated MTCS data. First, to illustrate the overall impact of MTCS data, electrical conductivity calculations were performed for each of the legacy sources in Table 6 [2, 9, 17, 24], along those utilizing the updated MTCS data correlations presented in Table 5. Figure 9 shows this comparison for the cases of oxy-combustion and air-fired combustion w/ $1500 \mathrm{~K}$ preheat (composition shown in Fig. 6). For both cases, there is $\sim 23 \%$ variation in electrical conductivity among legacy sources. For the air-fired combustion case, utilizing the updated MTCS data from Table 5 produces a value near that of utilizing MTCS data from Rosa [2]. For the oxy-combustion case, the updated MTCS data from Table 5 results in a value which is significantly 
higher than all legacy sources considered. This can be primarily attributed to updated data for $\mathrm{H}_{2} \mathrm{O}$ and $\mathrm{OH}$ species, for which the impact on electrical conductivity is especially high in the oxy-combustion case.

Figure 10 shows the calculated electrical conductivity corresponding to the data and seed levels in Fig. 8, for both seed level conventions. It can be seen that electrical conductivity in the oxy-combustion case is approximately double that of the air-fired case, even with $1500 \mathrm{~K}$ of preheat. Considering the approximation given by Eq. 1, this will translate to roughly a doubling of power generation in the MHD channel. Overall shape of the electrical conductivity profiles is similar to that of the electron concentrations, however the peaks are less broad. In particular, the electrical conductivity decreases more quickly with increasing seed level compared to the electron concentration. This is likely due to the increased water concentration from the seed solution, which, as shown above, has the potential to interact with electrons the most, decreasing the electrical conductivity. This is further supported by the fact that electrical conductivity drops much more quickly for oxycombustion, in which $\mathrm{H}_{2} \mathrm{O}$ species importance is higher compared to the air-fired case (see Fig. 7).

By comparing Fig. 8 and Fig. 10, it can be seen that the optimal seed level for peak electron production is generally higher than that of peak electrical conductivity. In Fig. 10 (a), for the air-fired case with preheat, peak electrical conductivity is achieved near $1.5 \% \mathrm{Y}_{\mathrm{K}}$, which is within the $\sim 1-2 \%$ value stated by legacy publications [2, $3,9,23,73$ ]. For peak electrical conductivity in the oxy-combustion system, $Y_{K}$ is near $3 \%$. When removing the effects of dilution by $\mathrm{N}_{2}$ in air to facilitate a more direct comparison, optimal seeding in the oxy-combustion system is achieved at $\sim 0.15 \mathrm{~m}_{\mathrm{K}} / \mathrm{m}_{\mathrm{CH} 4}$, approximately half of the mass required by the air-fired case ( 0.3 $\mathrm{m}_{\mathrm{K}} / \mathrm{m}_{\mathrm{CH} 4}$ ) while achieving roughly double the electrical conductivity.

As previously stated, gas temperature is extremely important in the thermal ionization of seed compounds leading to the formation of an electrically conductive combustion plasma. In particular, the sensitivity with which the resulting electrical conductivity, and thus MHD generator power, exhibit with respect to temperature. In order to examine temperature sensitivity for the oxy-combustion and legacy air-fired combustion systems, additional simulations were run for conditions of constant temperature and pressure. Temperatures were considered from $2000 \mathrm{~K}$ to each systems' corresponding adiabatic flame temperature at a given seed level. This comparison allows an examination of how electrical conductivity may vary in a practical system operating at reduced temperatures due to heat loss, as well as demonstrating the effect that gas composition can have at a given temperature. Note that this still represents an ideal scenario, and does not include considerations for finite rate kinetics and multiphase seed decomposition processes.

Figure 11 shows the results of this comparison for oxy-combustion and air-fired combustion with $1500 \mathrm{~K}$ preheat at the optimal seed levels identified from Fig. $10,0.15$ and $0.3 \mathrm{~m}_{\mathrm{K}} / \mathrm{m}_{\mathrm{CH} 4}$, respectively. First, it can be clearly seen that the peak electrical conductivity which can be achieved is significantly higher for the oxy-combustion case compared to air-fired with preheat. This was also apparent in Fig. 9 and Fig. 10. However more interesting is the fact that at a comparable temperature which can be achieved by air-fired combustion, the electrical conductivity of the oxy-combustion system is actually lower. This is a direct result of the increased significance of species such as $\mathrm{H}_{2} \mathrm{O}$ and $\mathrm{OH}$, which have large MTCS and collide more frequently with free electrons, causing a reduction in electrical conductivity (illustrated in Fig. 7). This is a similar result shown in [23], for oxy-combustion versus air-fired combustion at equivalent temperatures and seeding levels. 


\section{Conclusions}

A gas electrical conductivity model for use in open-cycle MHD power generation applications is presented, which makes use of updated MTCS data not represented in previous publications. An extensive MTCS data literature survey was performed, which included legacy MHD-oriented sources as well as newer publications directed toward the general plasma physics audience. MTCS data were analyzed for product gas species typical of hydrocarbon combustion, noting significant source discrepancies and identifying atomic potassium, $\mathrm{KOH}, \mathrm{OH}$, and $\mathrm{H}_{2} \mathrm{O}$ as species of particular interest. Sources of possible experimental electrical conductivity validation data for oxy-combustion were discussed, leading to a preliminary comparison of model predictions to published results from Dixit et al. [73] and Brogan [22] (Rosa [2]). Overall good agreement was observed, with model predictions falling in between the two experimental data sets.

A parametric study was performed, highlighting differences between the modern, oxy-combustion MHD system and the air-fired approach utilizing high levels of preheat. Compositional differences were noted, however more significant was the overall difference in species collisional frequencies, which dictate the gas electrical conductivity. For the oxy-combustion system, $\mathrm{H}_{2} \mathrm{O}$ and $\mathrm{OH}$ species importance was significantly higher, supporting the need for improved MTCS data consistency to enable accurate model predictions in these systems. Results were presented as a function seed level, noting approximately twice the electrical conductivity in the oxy-combustion system, at an optimal seed level which was half that of the air-fired system with $1500 \mathrm{~K}$ preheat. Finally, temperature sensitivity was examined with respect to electrical conductivity. At equivalent temperatures, the air-fired system out-performs the oxy-combustion system due to increased electron collisions in the plasma. This difference is primarily caused by the fact that $\mathrm{N}_{2}$ has a much smaller MTCS magnitude compared to $\mathrm{H}_{2} \mathrm{O}$. Still, it can be expected that oxy-combustion systems are capable of achieving notably higher electrical conductivities than were previously considered for combustion driven MHD, due to the increased temperatures and the high sensitivity of electrical conductivity above $\sim 2500 \mathrm{~K}$. This enables the possibility of much higher MHD power densities. However, full system techno-economic optimization will be required to conclusively indicate practical configurations for the target application.

\section{Acknowledgements}

This technical effort was performed in support of the National Energy Technology Laboratory's ongoing research under the RES contract DE-FE0004000.

Disclaimer: The project was funded by the Department of Energy, National Energy Technology Laboratory, an agency of the United State Government. Neither the United States Government nor any agency thereof, nor any of their employees, makes any warranty, expressed or implied, or assumes any legal liability or responsibility for the accuracy, completeness, or usefulness of any information, apparatus, product, or process disclosed, or represents that its use would not infringe privately owned rights. Reference herein to any specific commercial product, process, or service by trade name, trademark, manufacturer, or otherwise, does not necessarily constitute or imply its endorsement, recommendation, or favoring by the United States Government or any agency thereof. The views and opinions of authors expressed herein do not necessarily state or reflect those of the United States Government or any agency thereof. 


\section{References}

[1] NETL, Advancing oxycombustion technology for bituminous coal power plants: An R\&D guide, 2012.

[2] R.J. Rosa, Magnetohydrodynamic Energy Conversion, Hemisphere Publishing Corporation Washington, D.C., 1987.

[3] M. Petrick, B.Y. Shumyatsky, Open cycle magnetohydrodynamic electrical power generation, Argonne National Laboratory, 1978.

[4] Cantera: Chemical Kinetics, Thermodynamics, Transport Processes. www.cantera.org (accessed March 2015). [5] B.J. McBride, S. Gordon, M.A. Reno, Coefficients for Calculating Thermodynamic and Transport Properties of Individual Species, NASA Report TM-4513 (1993).

[6] B.J. McBride, S. Gordon, Computer Program for Calculation of Complex Chemical Equilibrium Composition, Rocket Performance, Incident and Reflected Shocks and Chapman-Jouget Detonations, NASA Report SP-273 (1971).

[7] K.H. Stern, E.L. Weise, High temperature properties and decomposition of inorganic salts, National Standard Data Reference System 30 (1969).

[8] R.H. Lamoreaux, D.L. Hildenbrand, High temperature vaporization behavior of oxides. I. Alkali metal binary oxides, J. Phys. Chem. Ref. Data 13 (1984).

[9] L.S. Frost, Conductivity of seeded atmospheric pressure plasmas, Journal of Applied Physics 32 (1961).

[10] R.J. Rosa, C.H. Krueger, S. Shioda, Plasmas in MHD power generation, IEEE Transactions on plasma science 19 (1991) 1180-1190.

[11] S.C. Lin, E.L. Resler, A. Kantrowitz, Electrical conductivity of highly ionized argon, Journal of Applied Physics 26 (1955) 40.

[12] A. Fridman, L.A. Kennedy, Plasma physics and engineering, Taylor and Francis, New York, NY, 2004.

[13] Y. Itikawa, Cross Sections for Electron Collisions With Carbon Dioxide, Journal of Physical and Chemical Reference Data 31 (2002) 749-767.

[14] Y. Itikawa, N. Mason, Cross Sections for Electron Collisions with Water Molecules, Journal of Physical and Chemical Reference Data 34 (2005) 1-22.

[15] Y. Itikawa, Momentum-Transfer Cross Sections for Electron Collisions with Atoms and Molecules, Atomic Data and Nuclear Data Tables 14 (1974) 1-10.

[16] Y. Itikawa, Momentum-Transfer Cross Sections for Electron Collisions with Atoms and Molecules Revision and Supplement, 1977, Atomic Data and Nuclear Data Tables 21 (1978) 69-75.

[17] F.E. Spencer, A.V. Phelps, Momentum Transfer Cross Sections and Conductivity Integrals for Gases of MHD Interest, 15th Symposium on Engineering Aspects of Magnetohydrodynamics, The University of Pennsylvania, Philadelphia, 1976, pp. IX.9.1-IX.9.8.

[18] L.A. Collins, D.W. Norcross, G.B. Schmid, Electron collisions with highly polar molecules: integrated and momentum transfer cross sections and conductivity integrals for $\mathrm{KOH}$ and $\mathrm{CsOH}$, Journal of Physics B: Atomic and Molecular Physics 12 (1979) 1019-1030.

[19] Y. Itikawa, Cross Sections for Electron Collisions with Nitrogen Molecules, Journal of Physical and Chemical Reference Data 35 (2006) 31-53.

[20] S. Schweitzer, M. Mitchner, Electrical conductivity of partially ionized gases, American Institute of Aeronautics and Astronautics 4 (1966) 1012-1019.

[21] M. Yousfi, M.D. Benabdessadok, Boltzmann equation analysis of electron-molecule collision cross sections in water vapor and ammonia, Journal of Applied Physics 80 (1996) 6619-6630. 
[22] T.R. Brogan, Electrical properties of seeded combustion gases, Progress in Astronautics and Aeronautics, Academic Press Inc, New York, 1963, pp. 319-345.

[23] M.S. Sodha, B.K. Sawhney, A. Chandra, S.Q. Hussain, S.C. Kaushik, R.P. Sharma, A.K. Ghatak, Conductivity of seeded combustion products of acetylene systems, Combustion and Flame 28 (1977) 295-300.

[24] R. Bunde, H. Muntenbruch, J. Raeder, R. Volk, G. Zankl, Collision cross-sections for momentum transfer between electrons and heavy particles, in: J. Raeder (Ed.), MHD Power Generation: Selected Problems of Combustion MHD Generators, Springer-Verlag, Berlin, 1975, pp. 42-45.

[25] D.L. Moores, The scattering of electrons by potassium atoms, Journal of Physics B: Atomic and Molecular Physics 9 (1976) 1329-1349.

[26] E. Karule, R. Peterkop, Collisions of Slow Electrons with Alkali Atoms, 4th International Conference on the Physics of Electronic and Atomic Collisions, Quebec, Canada, 1965, pp. 134.

[27] R.E. Collins, B. Bederson, M. Goldstein, Differential Spin Exchange and the Elastic Scattering of Low-Energy Electrons by Potassium, Physical Review A 3 (1971) 1976-1987.

[28] P.J. Visconti, J.A. Slevin, K. Rubin, Absolute Total Cross Sections for the Scattering of Low-Energy Electrons by Rubidium, Cesium, and Potassium, Physical Review A 3 (1971) 1310-1317.

[29] D.W. Norcross, Unpublished model potential calculations.

[30] E. Karule, The spin polarization and differential cross sections in the elastic scattering of electrons by alkali metal atoms, Journal of Physics B: Atomic and Molecular Physics 5 (1972) 2051-2060.

[31] J. Cederberg, D. Olson, D. Rioux, T. Dillemuth, B. Borovsky, J. Larson, S. Cheah, M. Carlson, M. Stohler, The electric dipole moment and hyperfine interactions of KOH, Journal of Chemical Physics 105 (1996) 3361.

[32] D. Laine, J. Cederberg, D. Olson, S. Cheah, P. Zimmer, D. Rioux, B. Borovsky, M. Carlson, Molecular Beam Measurement of the Electric Dipole Moment of KOH, OSU International Symposium on Molecular Spectroscopy, Ohio State University 1995.

[33] S. Altshuler, Theory of Low-Energy Electron Scattering by Polar Molecules, Physical Review 107 (1957) 114117.

[34] K. Anzai, H. Kato, M. Hoshino, H. Tanaka, Y. Itikawa, L. Campbell, M.J. Brunger, S.J. Buckman, H. Cho, F. Blanco, G. Garcia, P. Limão-Vieira, O. Ingólfsson, Cross section data sets for electron collisions with $\mathrm{H} 2, \mathrm{O} 2, \mathrm{CO}$, CO2, N2O and H2O, The European Physical Journal D 66 (2012) 1-8.

[35] Itikawa Database (elastic cross sections). www.Ixcat.net (accessed July 2015).

[36] M. Hayashi, Bibliography of Electron and Photon Cross Sections with Atoms and Molecules Published in the 20th Century - Water vapour - Report No. NIFS-DATA-081, National Institute for Fusion Science, Japan, 2003.

[37] T.D. Mark, Y. Hatano, F. Linder, Atomic and molecular data for radiotherapy and radiation research: final report of a co-ordinated research programme - section 3.8. elastic and inelastic scattering of electrons, International Atomic Energy Agency, Austria, 1995.

[38] A.V. Phelps, Compilation of Electron Cross Sections Used by A.V. Phelps, University of Colorado Joint Institute for Laboratory Astrophysics, Boulder, Colorado.

[39] Phelps Database (effective cross sections). www.Ixcat.net (accessed July 2015).

[40] Morgan (Kinema Research Software) Database (effective cross sections). www. Ixcat.net (accessed July 2015).

[41] Hayashi Database (elastic cross sections). www.lxcat.net (accessed July 2015).

[42] J.L. Pack, R.E. Voshall, A.V. Phelps, Drift Velocities of Slow Electrons in Krypton, Xenon, Deuterium, Carbon Monoxide, Carbon Dioxide, Water Vapor, Nitrous Oxide, and Ammonia, Physical Review 127 (1962) 2084-2089.

[43] H. Cho, Y.S. Park, H. Tanaka, S.J. Buckman, Measurements of elastic electron scattering by water vapour extended to backward angles Journal of Physics B: Atomic, Molecular and Optical Physics 37 (2004) 625-634.

[44] J.H. Parker, J.J. Lowke, Theory of Electron Diffusion Parallel to Electric Fields. I. Theory, Physical Review 181 (1969) 290-301.

[45] J.J. Lowke, J.H. Parker, Theory of Electron Diffusion Parallel to Electric Fields. II. Application to Real Gases, Physical Review 181 (1969) 302-311. 
[46] R.S. Cohen, A.V. Phelps, Unpublished H2O data, Westinghouse Research Laboratories, Pittsburgh, 1969. [47] I. Shimamura, Scientific Papers of the Institute of Physical and Chemical Research, Saitama/Japan, 1989. [48] M. Hayashi, Atomic and molecular data for radiotherapy and radiation research: proceedings of an advisory group meeting organized by the international atomic energy agency, International Atomic Energy Agency, Vienna, Austria, 13-16 June, 1988, 1988.

[49] V.A. Bailay, W.E. Duncanson, On the behaviour of electrons amongst the molecules $\mathrm{NH} 3, \mathrm{H} 2 \mathrm{O}$, and $\mathrm{HCl}$ The London, Edinburgh, and Dublin Philosophical Magazine and Journal of Science: Series 710 (1930) 145-160.

[50] R.L. Chambers, I. Tuba, Properties of Combustion Gases for Magnetohydrodynamic Processes, Westinghouse Electric, 1962.

[51] Swarm Studies and Inelastic Electron-Molecule Collisions, 1 ed., Springer-Verlag, New York, 1987.

[52] J. Lowke, J. Rees, The Drift Velocities of Free and Attached Electrons in Water Vapour, Australian Journal of Physics 16 (1963) 447-453.

[53] J.F. Wilson, F.J. Davis, D.R. Nelson, R.N. Compton, O.H. Crawford, Electron transport and ion clustering reactions in water vapor and deuterated water vapor, The Journal of Chemical Physics 62 (1975) 4204-4212. [54] R. Crompton, J. Rees, R. Jory, The Diffusion and Attachment of Electrons in Water Vapour, Australian Journal of Physics 18 (1965) 541-552.

[55] H. Ryzko, Arkiv for Physik, (1966) 1.

[56] H.Z. Schlumbohm, Physik 184 (1965) 492.

[57] M. Hayashi, 45th Annual Gaseous Electronics Conference, American Physical Society Boston, MA, 1992, pp. 189.

[58] Biagi-v8.9 (Magboltz version 8.9) Database (elastic cross sections). www.lxcat.net (accessed July 2015).

[59] Biagi-v7.1 (Magboltz version 7.1) Database (elastic cross sections). www.lxcat.net (accessed July 2015).

[60] BSR Database (elastic cross sections). www.lxcat.net (accessed July 2015).

[61] IST-Lisbon Database (elastic cross sections). www.Ixcat.net (accessed July 2015).

[62] Morgan (Kinema Research Software) Database (elastic cross sections). www.lxcat.net (accessed July 2015).

[63] Puech Database (elastic cross sections). www.lxcat.net (accessed July 2015).

[64] SIGLO Database (effective cross sections). www.Ixcat.net (accessed July 2015).

[65] SIGLO Database (elastic cross sections). www.lxcat.net (accessed July 2015).

[66] J.-S. Yoon, M.-Y. Song, J.-M. Han, S.H. Hwang, W.-S. Chang, B. Lee, Y. Itikawa, Cross Sections for Electron Collisions with Hydrogen Molecules, Journal of Physical and Chemical Reference Data 37 (2008) 913-931.

[67] IST-Lisbon Database (effective cross sections). www.Ixcat.net (accessed July 2015).

[68] Y. Itikawa, M. Hayashi, A. Ichimura, K. Onda, K. Sakimoto, K. Takayanagi, M. Nakamura, H. Nishimura, T. Takayanagi, Cross Sections for Collisions of Electrons and Photons with Nitrogen Molecules, Journal of Physical and Chemical Reference Data 15 (1986) 985-1010.

[69] Hayashi Database (effective cross sections). www.lxcat.net (accessed July 2015).

[70] Y. Itikawa, A. Ichimura, Cross Sections for Collisions of Electrons and Photons with Atomic Oxygen, Journal of Physical and Chemical Reference Data 19 (1990) 637-651.

[71] Y. Itikawa, Cross Sections for Electron Collisions with Oxygen Molecules, Journal of Physical and Chemical Reference Data 38 (2009) 1-20.

[72] TRINITI Database (elastic cross sections). www.lxcat.net (accessed July 2015).

[73] N.S. Dixit, N. Venkatramani, V.K. Rohatgi, Measurement of temperature, electrical conductivity and ion density of seeded combustion plasmas, Energy Convers. Mgmt 27 (1986) 103-109.

[74] T.K. Naidu, A. Chandra, S.Q. Hussain, B.K. Sawhney, M.K. Sarkar, Variation of Conductivity of Seeded Combustion Products of Hydrocarbon Fuels with C/H Ratio, Combustion and Flame 31 (1978) 239-243.

[75] T.R. Brogan, J.F. Louis, R.J. Rosa, J.J. Stekly, A review of recent MHD generator work at the Avco-Everett Research Laboratory, Avco-Everett Research Laboratory, Third Symposium on the Engineering Aspects of Magnetohydrodynamics, 1962. 
[76] C.R. Woodside, Retrospective and prospective aspects of MHD power generation, MHD Power Generation Workshop, NETL, Washington, D.C., 2014.

[Fig. 1 included as TIFF file]

Figure 1. Open-cycle linear segmented faraday MHD power train

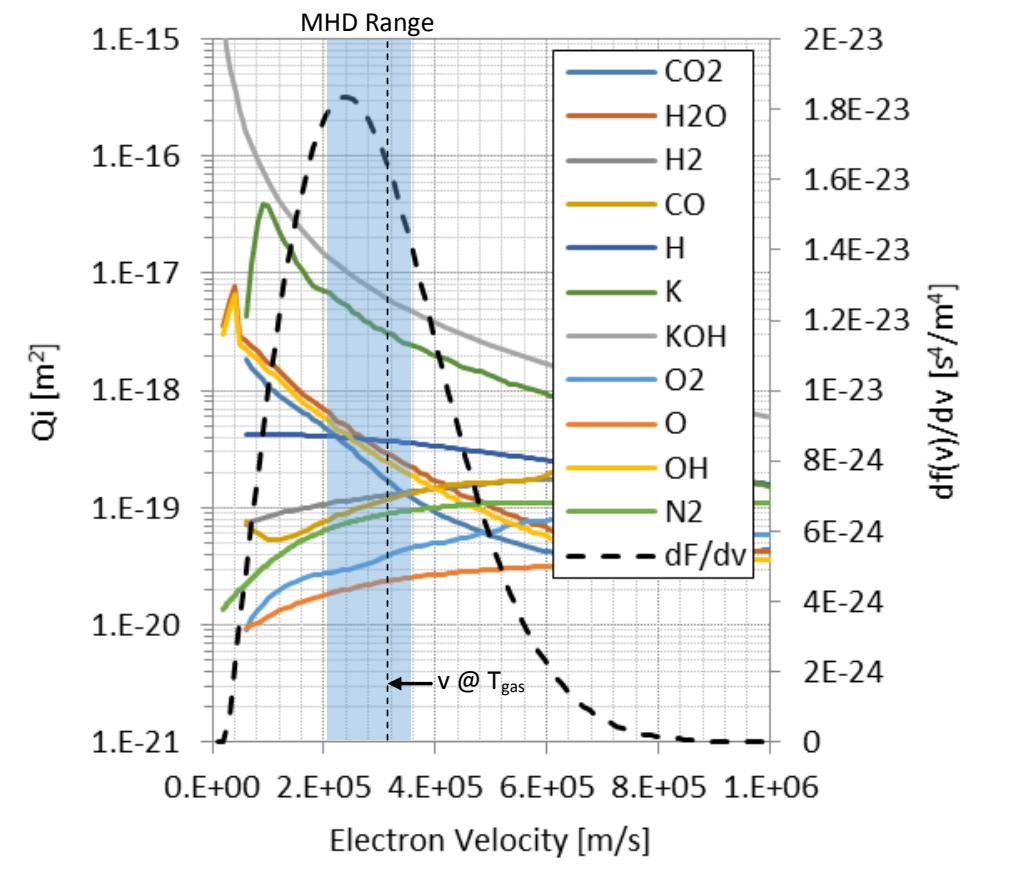

Figure 2. Maxwell-Boltzmann distribution (differentiated), collisional cross-section data [13-19] 


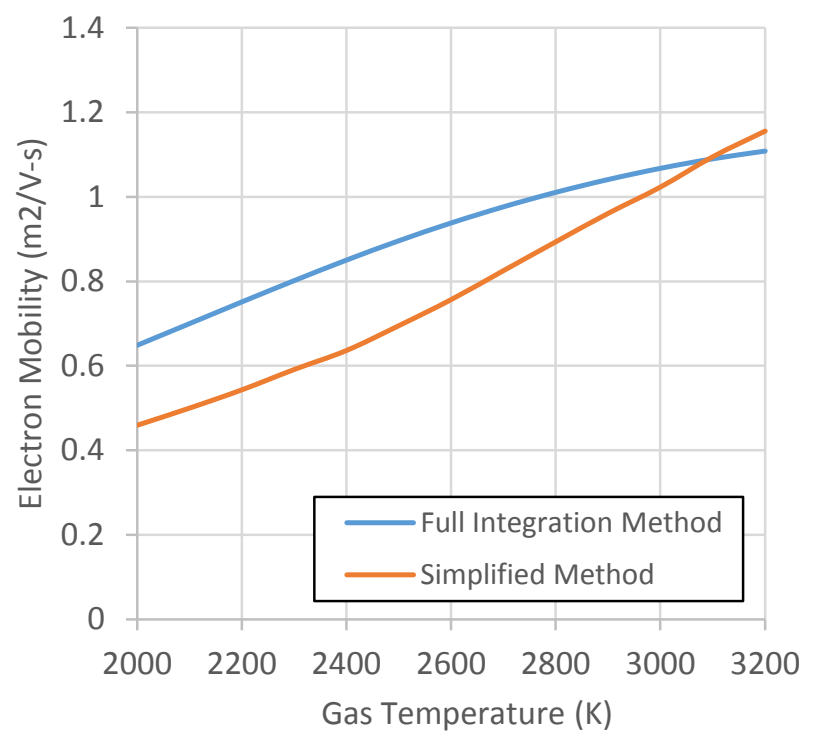

Figure 3. Electron mobility vs. temperature, oxygen-methane combustion, $1 \% \mathrm{Y}_{\mathrm{K}}$, full integration method, simplified method

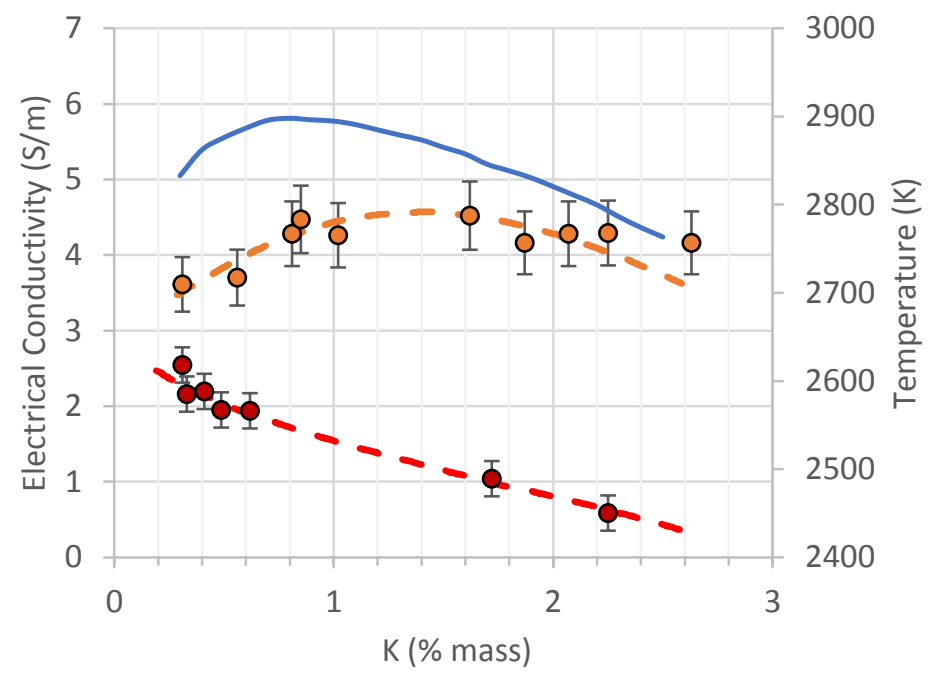

$$
\begin{array}{|cl}
\hline & \text { NETL model conductivity } \\
- & \text { Dixit et al. measured conductivity }(+/-10 \%) \\
- & \text { Dixit et al. conductivity best fit } \\
- & \text { Dixit et al. measured temperature }(+/-20 \mathrm{~K}) \\
- & \text { Dixit et al. temperature best fit } \\
\hline
\end{array}
$$

Figure 4. Electrical conductivity, temperature, Dixit et al.

[73] vs. model predictions 


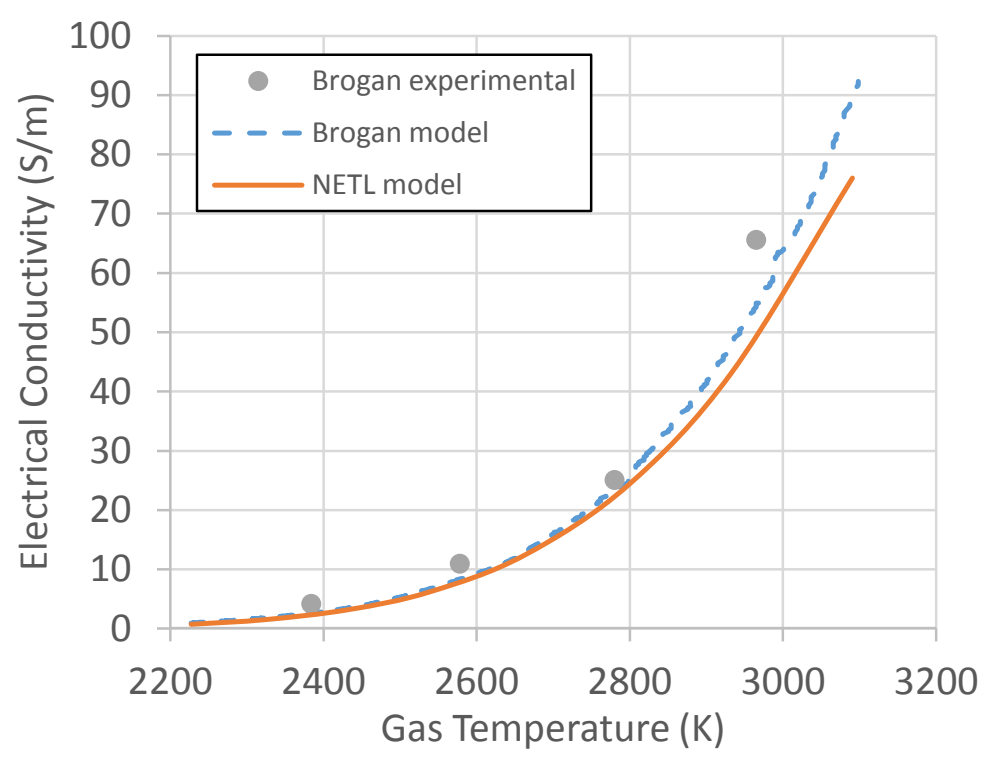

Figure 5. Electrical conductivity vs. temperature, $1 \% \mathrm{Y}_{\mathrm{K}}$, Brogan [22], model predictions

(a) Oxy-Combustion

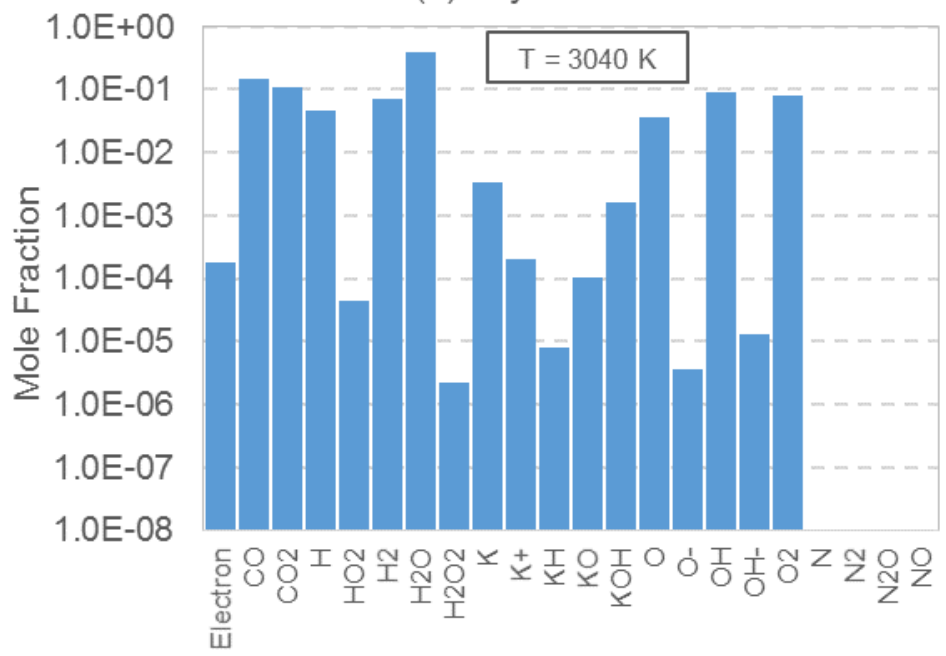

(b) Air-Fired w/ preheat

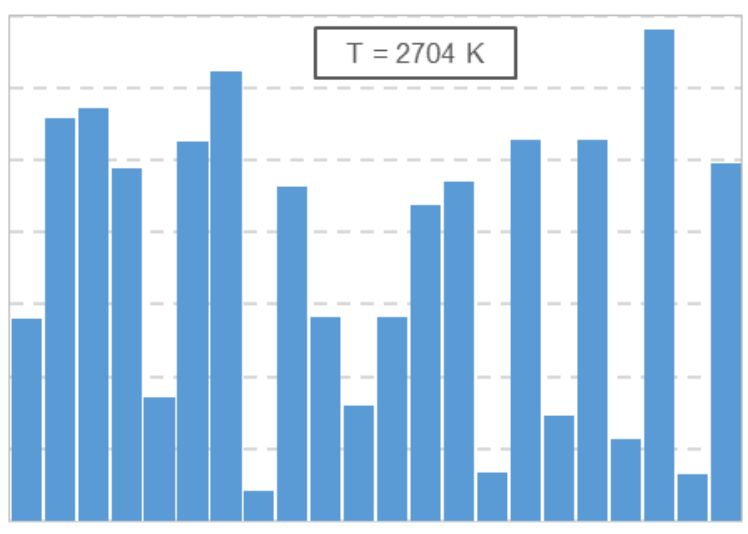

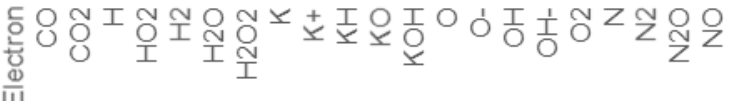

Figure 6. Product gas composition and temperature, $1 \% \mathrm{Y}_{\mathrm{K}},(\mathrm{a})$ oxy-combustion, (b) air-fired w/ $1500 \mathrm{~K}$ preheat 
(a) Oxy-Combustion

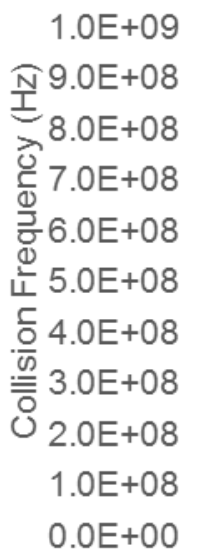

(b) Air-Fired w/ preheat

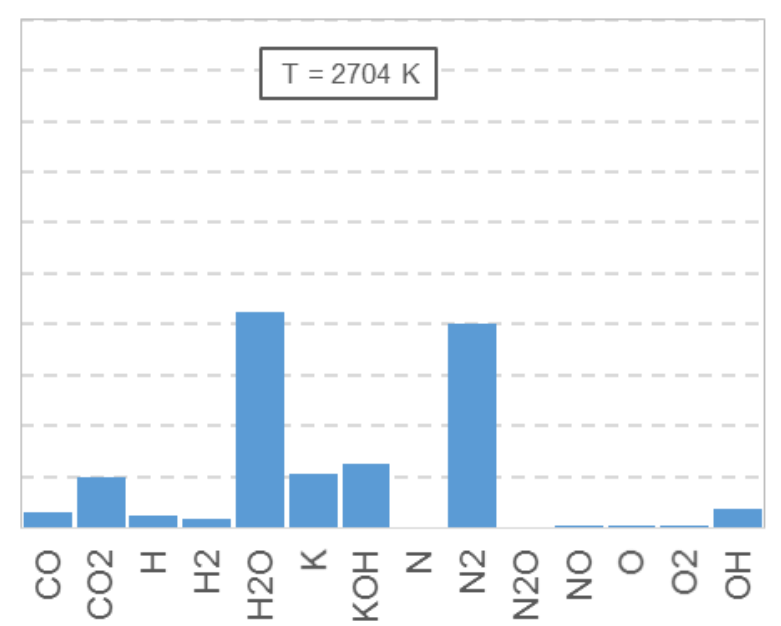

Figure 7. Species collision frequency $\left(v_{t i}\right), w /$ updated MTCS data from Table $5,1 \% Y_{k}$, (a) oxy-combustion, (b) air-fired $w / 1500 \mathrm{~K}$ preheat

(a)

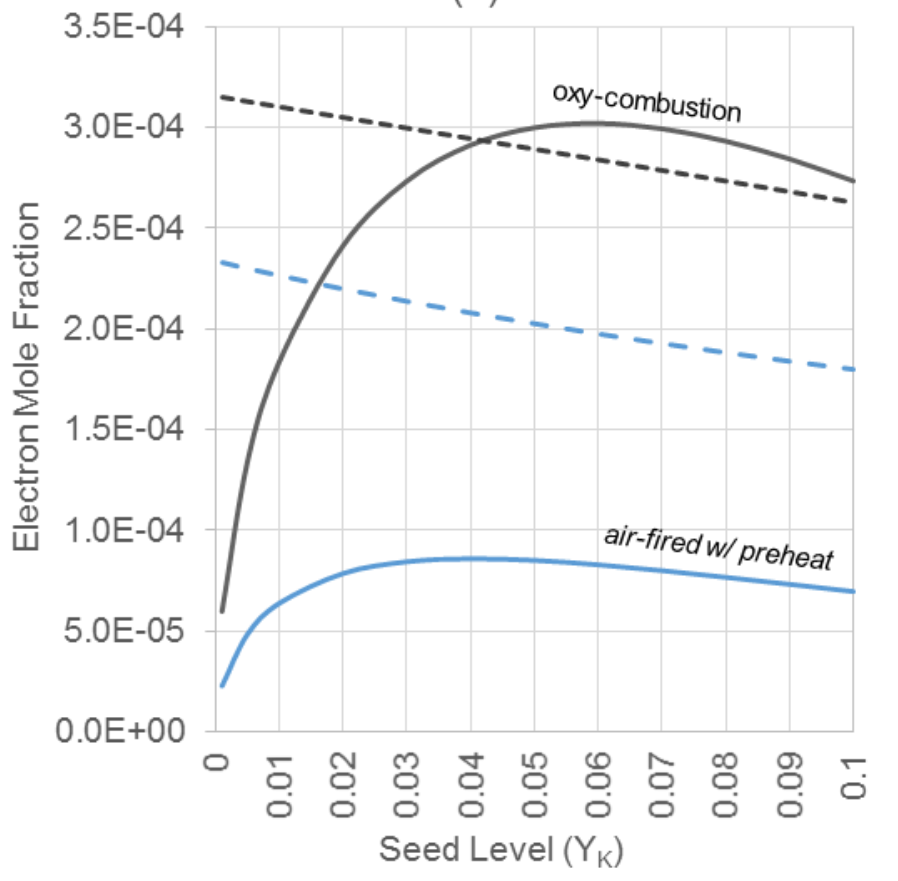

(b)



Figure 8. Electron concentration (-), temperature (- - ) vs. (a) seed mass fraction $Y_{K}$ and (b) seed mass ratio $\mathrm{m}_{\mathrm{K}} / \mathrm{m}_{\mathrm{CH} 4}$, oxy-combustion $(\bullet)$, air-fired $\mathrm{w} / 1500 \mathrm{~K}$ preheat $(\bullet)$ 


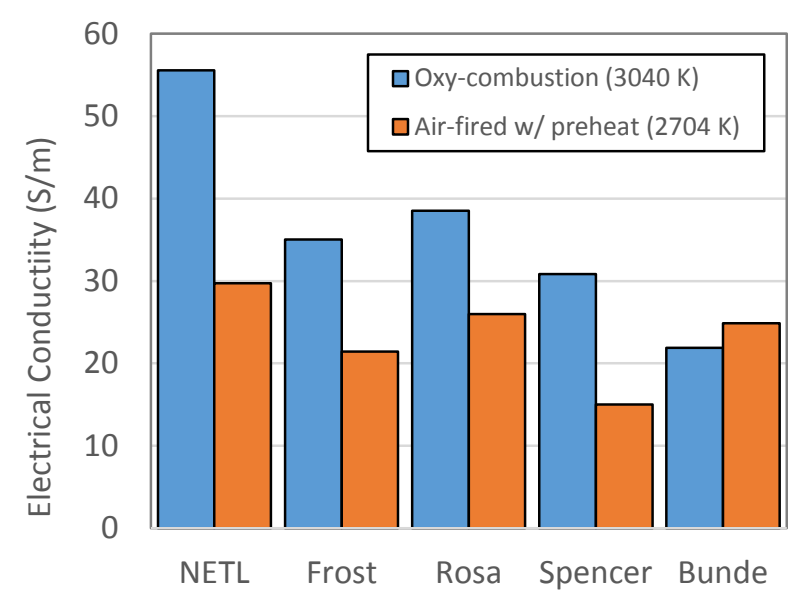

Figure 9. Electrical conductivity comparison among MHD-oriented legacy sources, $1 \% \mathrm{Y}_{\mathrm{k}}$, oxycombustion, air-fired $\mathrm{w} / 1500 \mathrm{~K}$ preheat

(a)

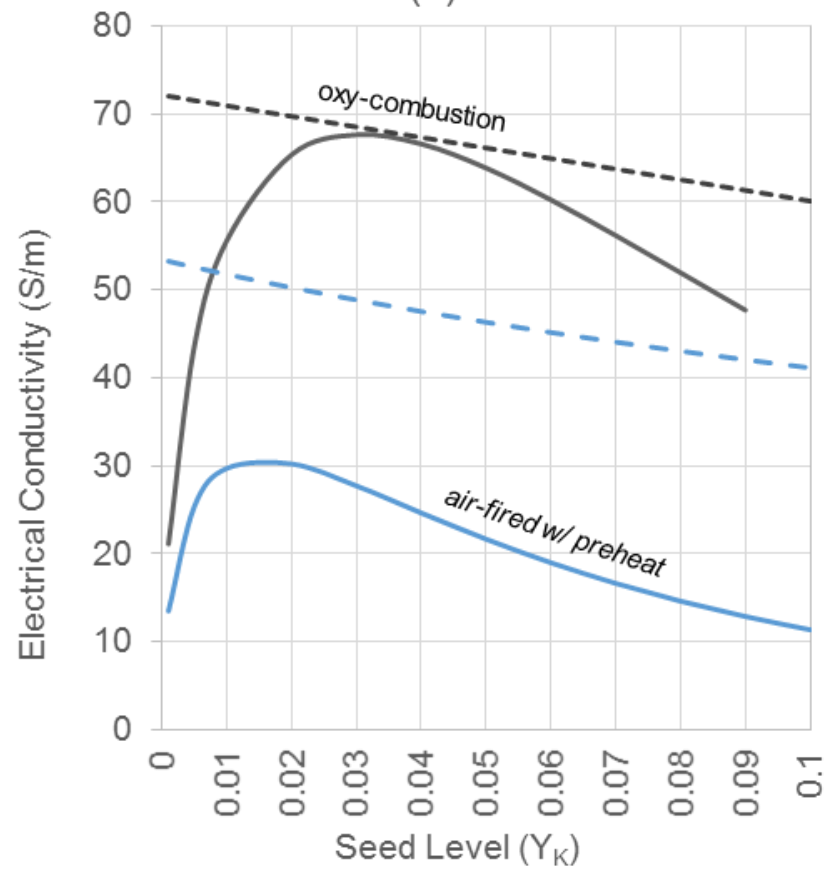

(b)

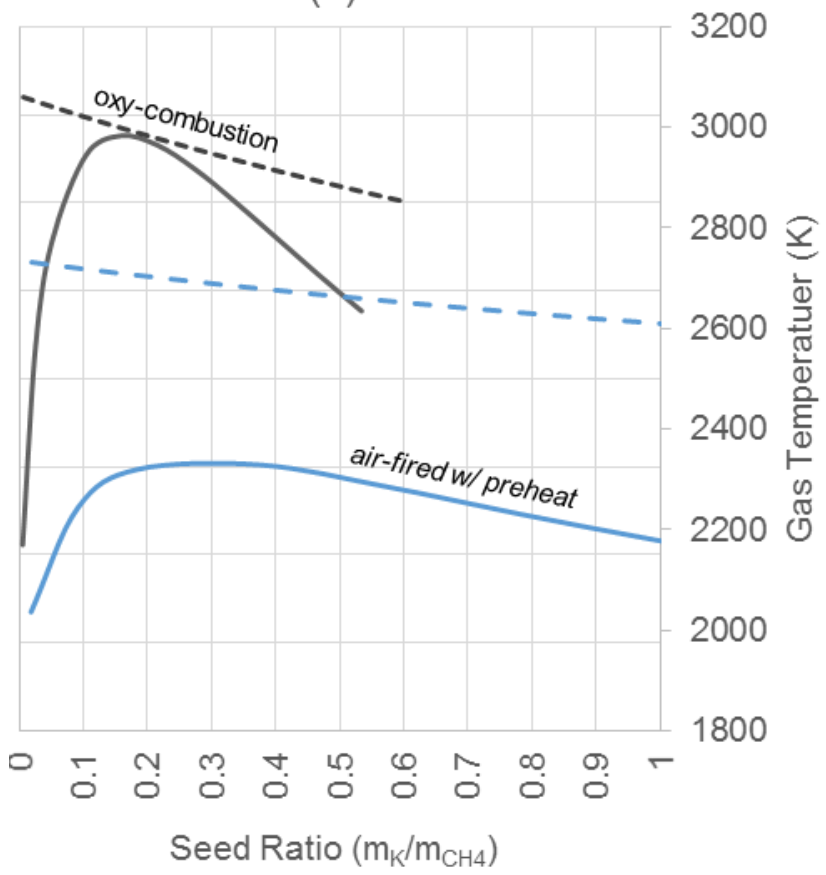

Figure 10. Electrical conductivity (-) and temperature (- - ) vs. (a) seed mass fraction $Y_{k}$ and (b) seed mass ratio $\mathrm{m}_{\mathrm{K}} / \mathrm{m}_{\mathrm{CH} 4}$, oxy-combustion $(\bullet)$, air-fired $\mathrm{w} / 1500 \mathrm{~K}$ preheat $(\bullet)$ 


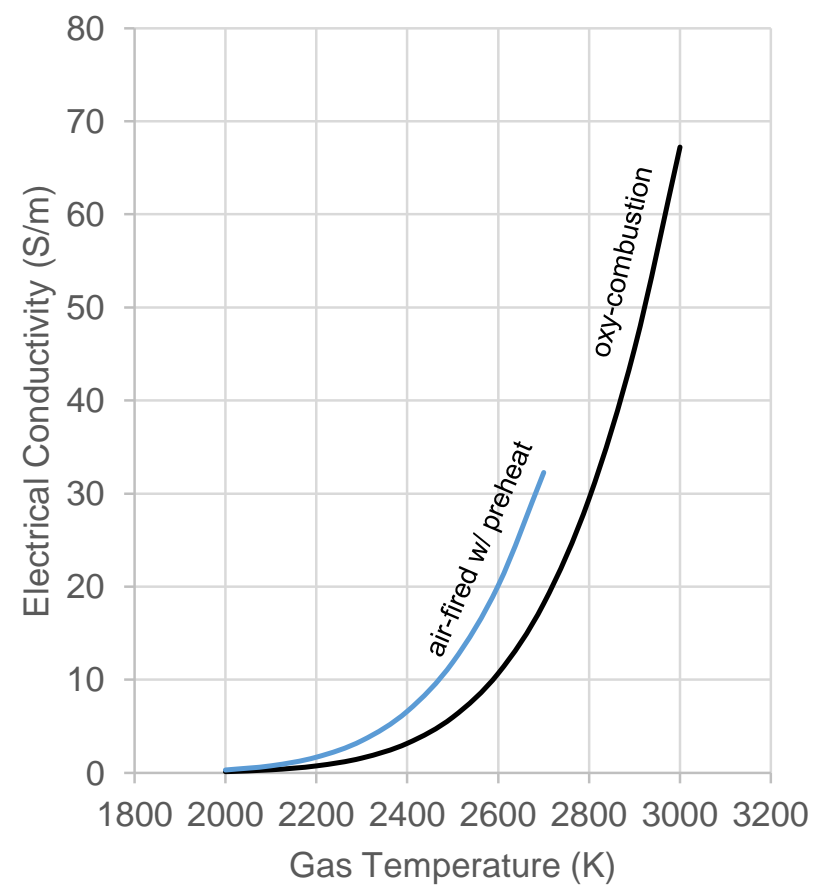

Figure 11. Electrical conductivity vs. temperature, oxy-combustion $\left(\bullet, 0.15 \mathrm{~m}_{\mathrm{K}} / \mathrm{m}_{\mathrm{CH} 4}\right)$ and air-fired w/ $1500 \mathrm{~K}$ preheat $\left(\bullet, 0.3 \mathrm{~m}_{\mathrm{K}} / \mathrm{m}_{\mathrm{CH} 4}\right)$ 